\title{
Target-Dependent Compartmentalization of the Corelease of Glutamate and GABA from the Mossy Fibers
}

\author{
들ilio J. Galván and Rafael Gutiérrez \\ Department of Pharmacobiology, Centro de Investigación y de Estudios Avanzados del Instituto Politécnico Nacional, 14330 México City, México
}

The mossy fibers (MFs) corelease glutamate and GABA onto pyramidal cells of CA3 during development, until the end of the third postnatal week. However, the major target cells of the MF are the interneurons of CA3. Therefore, it has been shown that the interneurons of the hilus and stratum lucidum receive this dual monosynaptic input on MF stimulation. Because the plasticity of glutamatergic transmission from the different terminals of the MF is target specific, we here asked whether the corelease of glutamate and GABA was also subjected to a target-dependent compartmentalization. We analyzed the occurrence and plasticity of MF simultaneous glutamatergic-GABAergic signaling onto interneurons of the different strata of CA3 in rats during the third postnatal week. We show the coexistence of time-locked, glutamate receptor and GABA receptor-mediated mono synaptic responses evoked by MF stimulation in interneurons from stratum lucidum and stratum radiatum, but not in interneurons from stratum lacunosum-moleculare. As expected from the transmission of MF origin, MF GABAergic responses were depressed by the activation of metabotropic glutamate receptors. Strikingly, while MF glutamatergic responses underwent LTD, the simultaneous MF GABAergic responses of stratum lucidum interneurons, but not of stratum radiatum interneurons, displayed a Hebbian form of LTP that was mimicked by PKC activation. PKA activation potentiated MF glutamatergic responses of stratum radiatum interneurons, whereas in stratum lucidum interneurons only GABAergic responses were potentiated. We here disclose that the corelease of glutamate and GABA, as well as their plasticity are compartmentalized in a target-dependent manner, showing counterbalanced compensatory plasticity of two neurotransmitters released by different terminals of the same pathway.

Key words: CA3; corelease; GABA; glutamate; interneurons; mossy fibers

Significance Statement

The mossy fibers transiently corelease glutamate and GABA onto pyramidal cells of CA3. We here describe that they can also corelease these amino acids onto interneurons, in a target-dependent manner. Many interneurons in stratum lucidum and stratum radiatum receive both signals, while those in stratum lacunosum-moleculare exclusively receive a glutamatergic signal. It is noteworthy that glutamatergic LTD, which is known to exist on stratum lucidum interneurons, coexists in the same pathway with a presynaptic form of GABAergic LTP, while interneurons of stratum radiatum, despite receiving this dual signaling, do not display such plasticity. The GABAergic LTP is mimicked with PKA or PKC activation. We disclose compartmentalized corelease of glutamate and GABA and its differential plasticity from a single pathway onto different interneuron sets.

\section{Introduction}

Plasticity of glutamate transmission from the granule cells of the dentate gyrus (DG) to pyramidal cells and interneurons in the CA3 region of the hippocampus is compartmentalized. Indeed,

\footnotetext{
Received June 14, 2016; revised Dec. 1, 2016; accepted Dec. 4, 2016.

Author contributions: E.J.G. and R.G. designed research; E.J.G. performed research; E.J.G. and R.G. analyzed data; E.J.G. and R.G. wrote the paper.

This work was supported by Grants 79408 and 10110/193/10 FIB.UBST.-29-1010 from Consejo Nacional de Ciencia y Tecnología, Mexico (to R.G.) and (B-2011-01-166241 and INFR-2012-01-187757 (to E.J.G.). E.J.G. was the recipient of a postdoctoral fellowship (Grant 79408) and now holds an independent position. We thank Diana Ixmatlahua and Gabriel Herrera-López for their help with cell labeling and anatomical reconstructions; Isabel Sollozo-Dupont for help with statistical analyses; and professors Juan Lerma and Enrico Cherubini for insightful comments during the preparation of the manuscript.

The authors declare no competing financial interests.
}

the anatomically different synaptic terminals of the axons of the granule cells, the mossy fibers (MFs), display plastic properties unique to the type of postsynaptic target they make contact with (Acsády et al., 1998; Maccaferri et al., 1998). On the other hand, it has been established that the granule cells not only release glutamate, but also express all of the markers of the GABAergic phenotype and release GABA during development (Walker et al., 2001; Gutiérrez et al., 2003; Gómez-Lira et al., 2005; Gutiérrez,

Correspondence should be addressed to either Dr. Rafael Gutiérrez or Dr. Emilio J. Galván, Department of Pharmacobiology, Centro de Investigación y Estudios Avanzados del Instituto Politécnico Nacional, Calzada de Ios Tenorios No. 235, Colonia Granjas Coapa C.P., México City 14330, México. E-mail: rafagut@cinvestav.mx or ejgalvan@cinvestav.mx.

DOI:10.1523/JNEUROSCI.1915-16.2016

Copyright $\odot 2017$ the authors $\quad 0270-6474 / 17 / 370701-14 \$ 15.00 / 0$ 
2005; Safiulina et al., 2006). Moreover, it has been directly shown that MF giant boutons can evoke glutamate-only, GABA-only, or mixed glutamate-GABA responses on CA3 pyramidal cells (Beltrán and Gutiérrez, 2012). However, in accordance with the true Dale's principle that all terminals of the same neuron must release the same neurotransmitters (Gutiérrez, 2009), monosynaptic GABAergic responses evoked by MF activation should also occur on interneurons, which constitute their primary targets. Indeed, evidence has been presented of GABA-mediated responses on interneurons of the hilus and in stratum lucidum of CA3 on MF stimulation (Bergersen et al., 2003; Romo-Parra et al., 2003; Safiulina et al., 2006). The MF-mediated GABAergic responses characterized in pyramidal cells follow the "principles" of transmission of MF origin [Walker et al., 2001; Gutiérrez et al., 2003; Safiulina et al., 2006; Beltrán and Gutiérrez, 2012; i.e., strong frequency potentiation and depression by activation of metabotropic glutamate receptors (mGluRs); Nicoll and Schmitz, 2005].

Most studies have examined the corelease of glutamate and GABA on pyramidal cells, which are contacted by MF giant boutons, from which the corelease of these amino acids has been directly observed (Beltrán and Gutiérrez, 2012). However, no detailed analysis of the glutamate-GABA corelease has been conducted in the terminals known to exclusively contact interneurons, the filopodial extensions and boutons en passant (Acsády et al., 1998). Importantly, PKA and PKC signaling has a critical role in MF plasticity of glutamatergic transmission on CA3 neurons. Indeed, adenylate cyclase activation with forskolin (FSK) mimics the MF LTP on CA3 pyramidal cells (Weisskopf et al., 1994; Villacres et al., 1998; Calixto et al., 2003), and PKC also strengthens glutamatergic transmission at MF synapses onto pyramidal cells and interneurons (Son and Carpenter, 1996; Honda et al., 2000; Alle et al., 2001; Hussain and Carpenter, 2005; Galván et al., 2010, 2015). From this evidence, it is reasonable to postulate that the putative release of GABA from fibers in which the activation of PKA potentiates glutamatergic transmission should also be potentiated. Remarkably, adenylate cyclase stimulation with forskolin induces the potentiation of MF GABAergic signaling on CA3 pyramidal cells (Walker et al., 2001). On the other hand, MF glutamatergic currents recorded from stratum lucidum interneurons are insensitive to FSK (Maccaferri et al., 1998; McBain et al., 1999), but MF glutamatergic responses of several subpopulations of interneurons undergo potentiation involving postsynaptic kinases (Galván et al., 2010, 2015). Finally, the expression of the markers of the GABAergic phenotype in the granule cells as well as the monosynaptic GABAergic responses evoked in pyramidal cells by MF stimulation disappears after the third week of life (Gutiérrez et al., 2003). Therefore, the same age-dependent switch off of MF GABAergic transmission onto interneurons is to be expected.

Thus, because MF glutamatergic transmission is highly specific according to its target cell type (Maccaferri et al., 1998; McBain, 2008; Galván et al., 2011), and because the integration of these inputs by the different target cells should be orchestrated to avoid disruption of the excitation-inhibition balance, here we examined MF glutamatergic-GABAergic cotransmission onto interneurons present in the different strata of CA3 area and its plastic characteristics.

\section{Materials and Methods}

The Ethics Committee for Animal Research of our institution approved all experimental procedures, which were performed in adherence to the
National Institutes of Health Guide for the Care and Use of Laboratory Animals (eighth edition).

Slice preparation. Male Wistar rats (13- to 17-d-old) were deeply anesthetized (pentobarbital, $50 \mathrm{mg} / \mathrm{kg}$, i.p.), brains were rapidly removed, and transversal hippocampal slices of $375 \mu \mathrm{m}$ were obtained with a Vibroslicer (model VT1200, Leica) submerged in a sucrose-based cutting solution containing the following (in $\mathrm{mm}$ ): sucrose $230, \mathrm{KCl} 1.9$, $\mathrm{NaH}_{2} \mathrm{PO}_{4} 1.2, \mathrm{NaHCO}_{3} 25$, glucose $10, \mathrm{CaCl}_{2} 1$, and $\mathrm{MgCl}_{2} 4$ at $2^{\circ} \mathrm{C}$ (Galván et al., 2008). Slices were maintained for at least $120 \mathrm{~min}$ in an incubation solution with the following composition (in $\mathrm{mm}$ ): $125 \mathrm{NaCl}$, $2 \mathrm{KCl}, 1.2 \mathrm{NaH}_{2} \mathrm{PO}_{4}, 25 \mathrm{NaHCO}_{3}, 10$ glucose, $1 \mathrm{CaCl}_{2}$, and $6.0 \mathrm{MgCl}_{2}$, pH 7.3 maintained with bubbled $\mathrm{O}_{2}(95 \%) / \mathrm{CO}_{2}(5 \%)$ at room temperature. For recording, the slices were transferred to a submersion recording chamber and superfused at constant flow $(3.5 \mathrm{ml} / \mathrm{min})$ with the following solution (in $\mathrm{mm}$ ), $125 \mathrm{NaCl} ; 3 \mathrm{KCl} ; 1.25 \mathrm{Na}_{2} \mathrm{HPO}_{4} ; 25$ $\mathrm{NaHCO}_{3} ; 2 \mathrm{CaCl}_{2} ; 1 \mathrm{MgCl}_{2} ; 10$ glucose; $\mathrm{pH} 7.3$, at room temperature $\left(24 \pm 3^{\circ} \mathrm{C}\right)$. Whole-cell recordings were obtained from the soma of putative interneurons in stratum lucidum, stratum radiatum, and stratum lacunosum-moleculare of area CA3b of the hippocampus. Cell bodies were localized between 50 and $100 \mu \mathrm{m}$ from the slice surface and identified visually with infrared video microscopy and differential interference contrast optics. Patch pipettes with electrical resistances of 5- $8 \mathrm{M} \Omega$ were pulled from borosilicate glass and filled with a solution containing the following (in mM): $125 \mathrm{~K}$-gluconate, $4 \mathrm{KCl}, 4 \mathrm{NaCl}, 10 \mathrm{HEPES}$, 1 EGTA, 2 Na-ATP, and 0.4 GTP.

Electrophysiological recordings. Current-clamp and voltage-clamp recordings were obtained with a Multiclamp 700B Amplifier (Molecular Devices), digitized and sampled at $10 \mathrm{kHz}$, and filtered at $5 \mathrm{kHz}$ (Digidata 1440A, Molecular Devices). Signals were acquired and analyzed off-line with pCLAMP10 software (Molecular Devices). The resting membrane potential (RMP) was measured after initial break in of the cell membrane. Interneurons were considered for analysis only if the access resistance was 5-11 M $\Omega$, a value that coincides with those in previous reports (Galván et al., 2008; Beltrán and Gutiérrez, 2012); interneurons were discarded if access resistance changed by $>15 \%$ of the initial value. For the experiments performed in current clamp, the access resistance was monitored every $15 \mathrm{~min}$ (in voltage clamp with a step pulse of $5 \mathrm{mV} / 20$ $\mathrm{ms}$ ) throughout the experiments. After the resting membrane potential of the cells was stabilized by voltage clamping for at least $5 \mathrm{~min}$, the amplifier was switched to current clamp. Then, a series of inward and outward current steps ( $1 \mathrm{~s}$ duration; $30 \mathrm{pA}$ increments at $0.2 \mathrm{~Hz}$ ) were injected via the recording pipette to assess input resistance (Rn), action potential amplitude, threshold, and afterhyperpolarization. Those parameters were used to classify the recorded interneurons. The input resistance was calculated as the slope of linear fit between voltage and injected current.

Stimulation technique. Extracellular stimulation was performed using bipolar stimulating electrodes made of nichrome wire, $62 \mu \mathrm{m}$ in diameter. Stimulation consisted of single monopolar pulses (100-200 $\mu \mathrm{A}$ intensity; $100-120 \mu$ s duration) at $0.16 \mathrm{~Hz}$ with a stimulator (S48, Grass Instruments) using a stimulus isolation unit (PSIU6, Grass Instruments). For the PKA or PKC stimulation experiments (see Fig. 3), the stimulation rate was reduced to $0.066 \mathrm{~Hz}$. To reduce the probability of antidromic stimulation of CA3 pyramidal cells and of the activation of CA3 collaterals, we used low current intensities, resulting in evoked responses with amplitudes $<30 \%$ of that required to fire action potentials $(2-3 \mathrm{mV})$. Paired-pulse facilitation (60 ms interstimulus interval) was assessed in current-clamp mode for both glutamatergic and GABAergic responses. Paired-pulse facilitation was calculated as the paired-pulse ratio of the amplitude of the second EPSP to that of the first in the pair.

Criteria for the identification of GABAergic LTP. LTP was induced by high-frequency stimulation (HFS) consisting of three trains of 100 pulses at $100 \mathrm{~Hz}$, repeated every $10 \mathrm{~s}$, and paired with a postsynaptic depolarizing current step $(250 \pm 40 \mathrm{pA})$ when the experiments were performed in current-clamp mode. This induction protocol generated strong postsynaptic firing on all the recorded interneurons. We assessed the changes in the strength of the GABAergic responses by measuring the amplitude of the evoked current. As previously reported for glutamatergic responses on hippocampal interneurons (Galván et al., 2008), we defined 
GABAergic LTP as stable potentiation of $>25 \%$ with respect to baseline for at least $30 \mathrm{~min}$ after high-frequency stimulation. Individual values from each experiment were normalized to its baseline magnitude before high-frequency stimulation (8 min stable baseline) for comparison across experiments.

Cell labeling and digital reconstruction. Neurobiotin tracer (Vector Laboratories) was routinely included in the pipette solution to allow subsequent identification and reconstruction of the recorded cells. Following data collection, the slices were fixed and stored overnight in a fixative solution containing 4\% paraformaldehyde dissolved in PBS, $\mathrm{pH}$ 7.4. After extensive washes in PBS, the sections were incubated in permeabilization solution containing $0.4 \%$ Triton X-100 in PBS for 90 min; the sections were incubated in avidin-biotinylated complex (Vectastain $\mathrm{ABC}$ Kit) for $2 \mathrm{~h}$. Following the PBS washes, neurobiotin labeling was visualized by nickel chloride-intensified 3,3'-diaminobenzidine as a chromogen (DAB Subtrate Kit, Vector Laboratories) at room temperature for $2 \mathrm{~min}$. Adding nickel chloride to the substrate working solution results in a gray-black reaction product. The sections were washed for 5 min in distilled water. They were then embedded in Vectashield mounting medium (Vector Laboratories). For the examination and digital reconstruction of the recorded cells, a microscope AxioScope A1 (Zeiss) was used. Sections were examined with light microscopy and a $40 \times$ objective. To display the shape and orientation of the cell, twodimensional reconstructions were accomplished using the distribution Fiji of the open-source software ImageJ.

Drugs. D(-)-2-amino-5-phosphonopentanoic acid (D-AP5), 6-cyano-7nitroquinoxaline-2,3-dione (CNQX), forskolin, and phorbol 12,13diacetate (PDA) were purchased from Sigma-Aldrich. Forskolin and PDA were dissolved in DMSO at concentrations of 100 and $2 \mu \mathrm{M}$, respectively, and then added to the bath solution. $\left(2 S, 2^{\prime} \mathrm{R}, 3^{\prime} \mathrm{R}\right)-2-\left(2^{\prime}, 3^{\prime}\right.$-dicarboxycyclopropyl)glycine (DCG-IV), or L-(+)-2-amino-4-phosphonobutyric acid (LAP4), were purchased from Tocris Bioscience.

Statistical analysis. Group measures are expressed as the means \pm SEM. To determine the statistical significance of the changes in amplitude, the mean IPSP amplitude baseline (GABAergic response) was compared with the mean IPSP amplitude at 25-30 min after highfrequency stimulation. The normality of the populations was systematically tested with the Kolmogorov-Smirnov test $(p<0.05)$, followed by one-way ANOVA and Student-Newman-Keuls pairwise comparisons $(p<0.05)$. The differences were considered significant at $p<0.05$. In the figures, statistical significance is denoted as follows: ${ }^{\star} p<0.05$ and ${ }^{* *} p<$ 0.001 (or higher).

\section{Results}

Interneurons of the stratum lacunosum and stratum radiatum but not of the stratum lacunosum-moleculare express an MF-mediated monosynaptic GABAergic response Whole-cell recordings were performed on interneurons located in stratum lucidum, stratum radiatum, and stratum lacunosummoleculare from acutely prepared hippocampal slices of 13- to 17 -d-old rats. Interneurons with somata located in stratum lucidum (Fig. 1A1) had an axonal arbor that extended along the stratum lucidum and into the stratum pyramidale. Their dendritic tree was extended mostly into stratum radiatum with some dendrites distributed in the stratum pyramidale. Interneurons with somata located in stratum radiatum (Fig. 1A2) extended their profuse axonal and dendritic trees in stratum radiatum with some extensions into stratum pyramidale and even stratum oriens.

An $I-V$ curve was used to identify passive properties, and the fire pattern was used to group them as fast-spiking interneurons (FSis; Fig. 1B1) or regular-spiking interneurons (RSis; Fig. 1B2). RMP and $\mathrm{Rn}$ from FSis and RSis were distinct to each subgroup (RMP for FSis, $-63 \pm 2 \mathrm{mV}, n=23$; RMP for RSis, $70.5 \pm 0.6 \mathrm{mV}, n=66 ; p<$ 0.001 ; Rn for FSis, $168 \pm 23.19 \mathrm{M} \Omega$, RN for RSis, $268.9 \pm 27.3 \mathrm{M} \Omega$; $p<0.01$, unpaired $t$ test). An MF-elicited response was obtained on stimulation of the granular cell layer of the DG during the steady state of the voltage response, $650 \mathrm{~ms}$ after the onset of the DC current step (1 s duration). Stimulation of the DG evoked monosynaptic MF responses in both types of interneurons (Fig. 1B1,B2). When the injected current step surpassed the resting membrane potential and depolarized the interneuron, an MF-evoked, hyperpolarizing postsynaptic response was unmasked. The compound MF-evoked excitatory and inhibitory response was found in 48 of 88 interneurons distributed through the stratum lucidum and stratum radiatum of area CA3. Notably, the MF-evoked inward responses were absent in 22 of 22 stratum lacunosum-moleculare interneurons. Both the EPSPs and IPSPs had similar time onsets (Fig. 1B1, top insets, B2). Next, to isolate the MF-evoked inhibitory response, we perfused the glutamate ionotropic receptor antagonists CNQX (100 $\mu \mathrm{M})$ and D-AP5 $(50 \mu \mathrm{M})$. The perfusion of the antagonists blocked the depolarizing responses and isolated a steady MF-evoked inhibitory response in fast-spiking interneurons (Fig. 1C1) and regular-spiking interneurons (Fig. 1C2) located in stratum lucidum and stratum radiatum. These results are in agreement with previous reports that demonstrated that during early postnatal development, MF synapses corelease glutamate and GABA on interneurons (Romo-Parra et al., 2003; Safiulina et al., 2006). To further corroborate the specificity of the inhibitory responses, in a set of experiments we activated two GABAergic inputs by placing a stimulation electrode in the stratum radiatum in addition to the electrode placed in the stratum lucidum and recorded IPSCs on the same interneuron (Fig. 1D). As expected, the MF-evoked IPSCs were depressed by perfusion of L-AP4 $10 \mu \mathrm{M}$ (63.2 $\pm 3.6 \%$ of inhibition; $p<0.001$, one-way ANOVA; Fig. $1 E 1, E 2)$, whereas the IPSCs evoked by the activation of a nearby neuron within CA3 were insensitive to L-AP4 (5.8 $\pm 3 \%$ of inhibition; $p=$ n.s; Fig. 1F1,F2).

\section{Interneurons of stratum lucidum express MF GABAergic LTP} Previous studies revealed that tetanic stimulation of the MFs induces a form of GABAergic LTP on CA3 pyramidal cells (Walker et al., 2001, Gutiérrez, 2002). However, because the plasticity of MF transmission on interneurons differs from that on pyramidal cells (Maccaferri et al., 1998), we investigated whether MF GABA transmission is capable of expressing long-term potentiation on interneurons. To test this hypothesis, MF IPSCs were isolated in stratum lucidum interneurons that exhibited an EPSP before the perfusion of CNQX plus D-AP5 (Fig. 1B1,B2). As expected, the perfusion of the glutamatergic antagonist blocked the MF-mediated glutamatergic response. Then, cells were voltage clamped at $-66 \mathrm{mV}$ in the presence of CNQX and D-AP5. Under these pharmacological conditions, the evoked MF IPSC had a mean amplitude of $74.5 \pm 21.2 \mathrm{pA}$ for both fast-spiking and regular-spiking interneurons. In addition, the fastspiking interneurons exhibited an IPSC rise time of $1.38 \pm 0.23 \mathrm{~ms}$ and a decay time constant of $7.01 \pm 1.41$, whereas the regularspiking interneurons had a mean rise time of $1.6 \pm 0.24(p=0.51)$ and a decay time constant of $8.2 \pm 2.04 \mathrm{~ms}(p=0.15)$. After a stable 8 min baseline of MF IPSCs, a train of high-frequency stimulation was delivered to the MFs ( $100 \mathrm{~Hz}$, three times, $10 \mathrm{~s}$ intervals), after which the amplitude of the MF IPSCs exhibited a sustained increase (fast-spiking interneurons, $175.3 \pm 4.1 \%$ of baseline at $35 \mathrm{~min}$ after HFS; $p<0.001$, one-way ANOVA; $n=6$ of 8 cells; regular-spiking interneurons, $178.24 \pm 6.21 \%$ of baseline at $35 \mathrm{~min}$ after HFS; $p<$ 0.001 , one-way ANOVA; $n=11$ of 16 cells; Fig. $2 A, B)$. Because potentiation after high-frequency stimulation was similar in both groups of stratum lucidum interneurons, they were pooled for the rest of the analyses. Bath application of the group III mGluR agonists, L-AP4 $(10 \mu \mathrm{M} ; n=11)$ or the group II mGluR agonist DCG-IV ( $5 \mu \mathrm{M} ; n=6)$ reverted the strength of the synaptic responses and confirmed the MF nature of the GABAergic response (fast-spiking interneurons, $52.67 \pm 3.6 \%$ of inhibition; $p<0.001$, one-way 

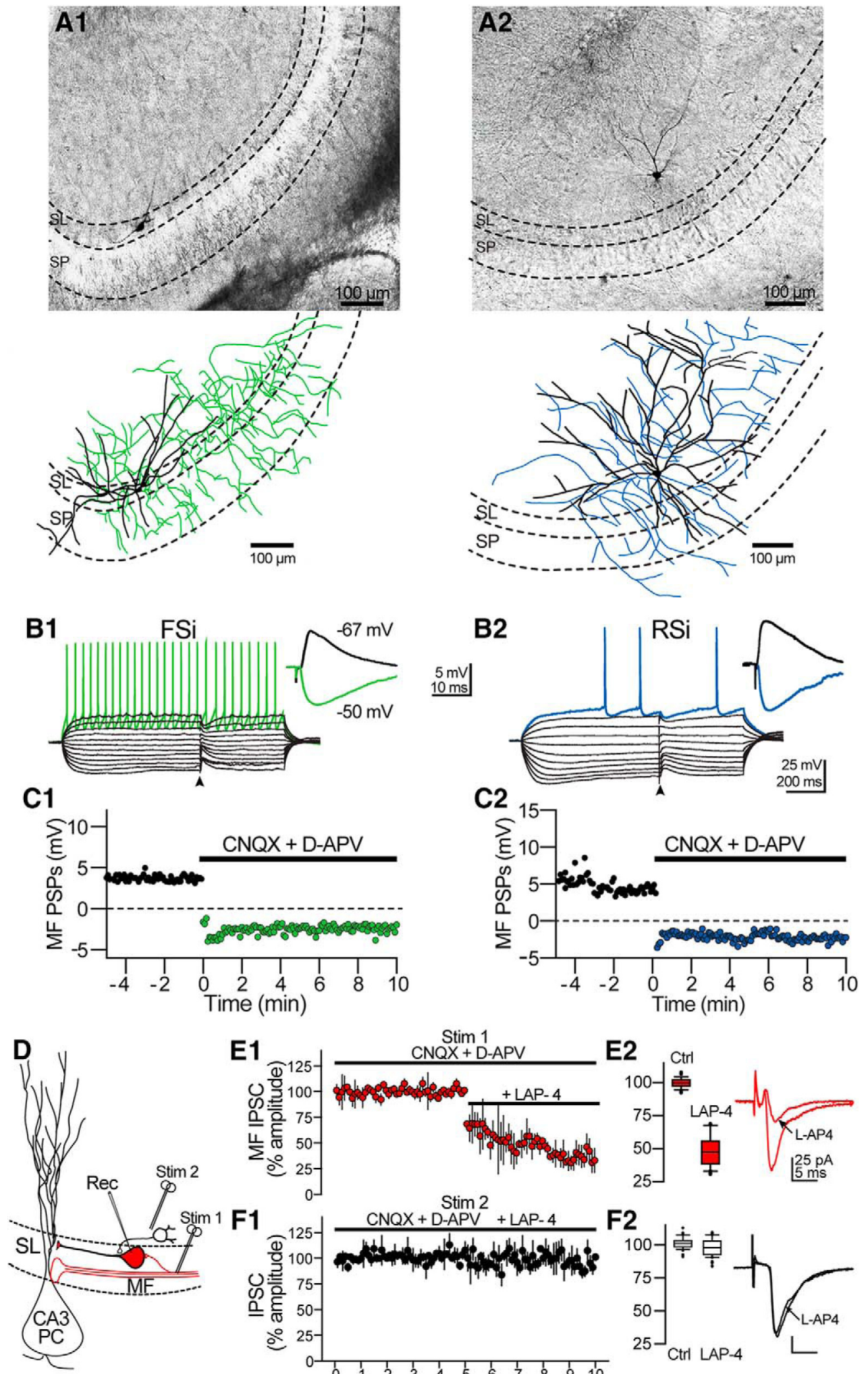

Stim 1

SeXtim 1
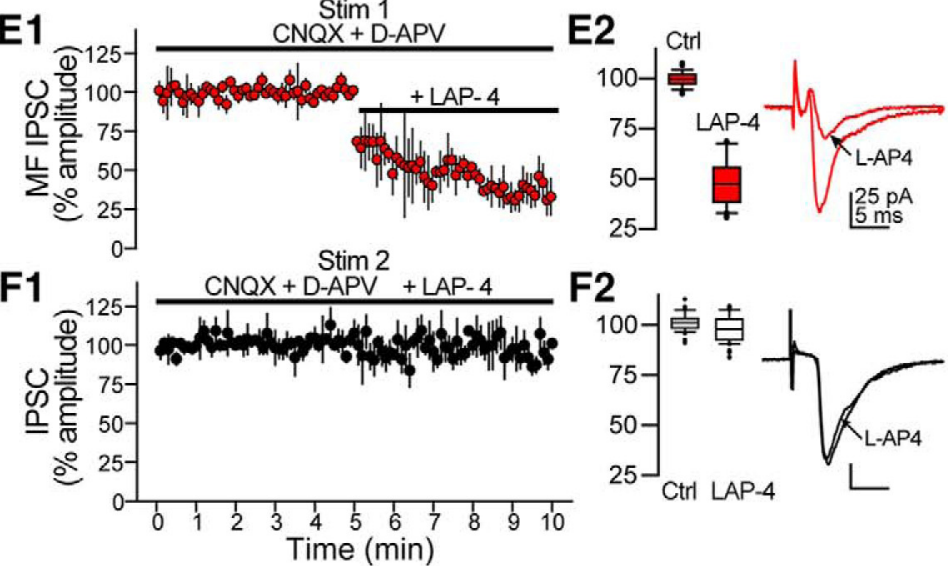

Figure 1. Mossy fiber activation evokes simultaneous, monosynaptic glutamate- and GABA receptor-mediated responses in CA3 interneurons. $\boldsymbol{A} \mathbf{1}, \boldsymbol{A 2}$, Representative micrographs of fast-spiking interneurons (A1) and regular-spiking interneurons (A2) filled with neurobiotin. Bottom, Digital reconstructions of the same interneurons. The somatic bodies of fast-spiking interneurons were located on the border of stratum pyramidale or in the stratum lucidum, whereas the bodies of regular-spiking interneurons were mainly distributed in the border of stratum lucidum and stratum radiatum. $B 1, B 2, I-V$ curves and fire pattern of the interneurons depicted in $A$. Corelease of glutamate and GABA was unmasked with MF stimulation applied during the steady state of the $I-V$ curves. The arrowheads under the voltage traces indicate MF stimulation. C1, C2, Synaptic responses evoked before and during the blockade of AMPA and NMDA receptors, which unmasked stable inhibitory postsynaptic responses without modification of their latency. $\boldsymbol{D}$, Schematic representation of the intrinsic circuitry of CA3 depicting two sites (Figure legend continues.) 
A

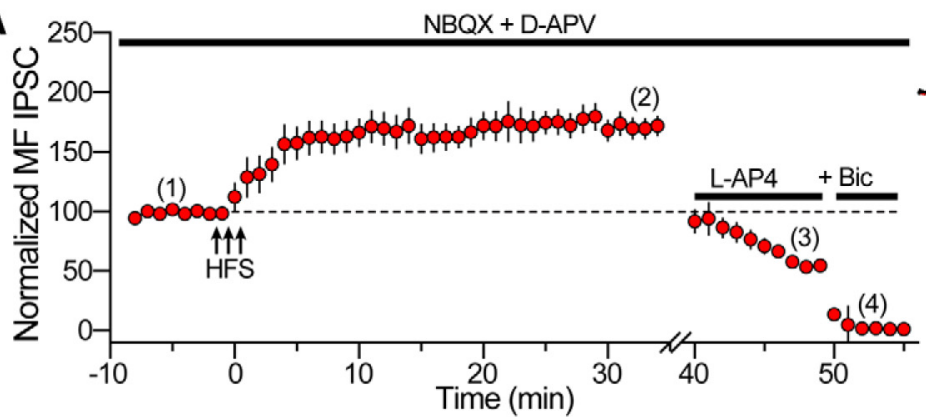

(4)

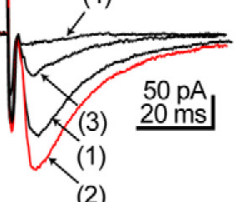

(2)
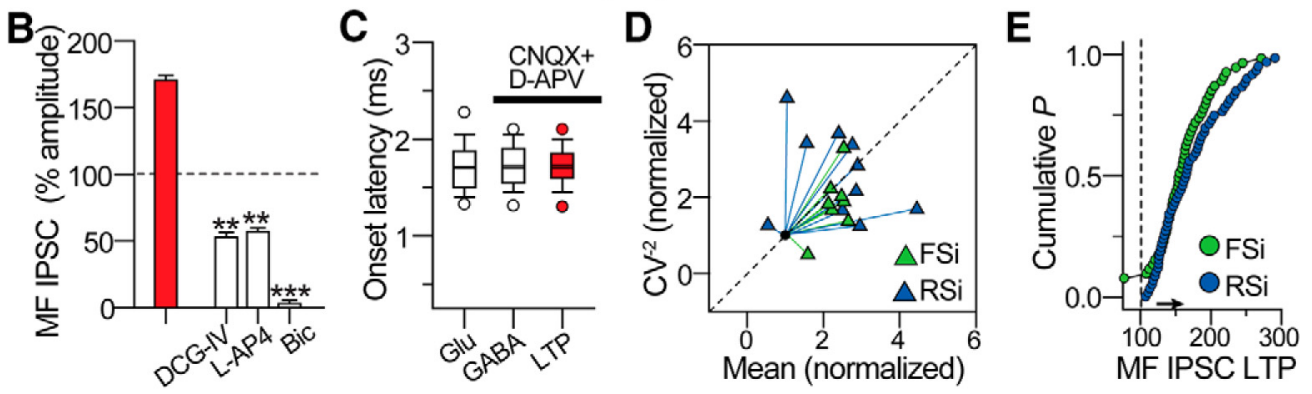

Figure 2. Stratum lucidum interneurons express presynaptic MF GABA LTP. A, Average time course graph $(n=18)$ of normalized IPSC slopes before and after HFS on the MFs. The HFS protocol yielded a potentiation of the MF IPSCs in both fast-spiking and regular-spiking interneurons that was partially depressed with the mGluRIII agonist L-AP4 and was totally blocked with bicuculline. Right, Representative traces from a regular-spiking interneuron (average of five consecutive sweeps) acquired at the indicated time in the time course graph. The responses were obtained in the presence of NBQX plus D-APV. B, Summary of the magnitude of MF IPSC potentiation after HFS and its sensitivity to the activation of the group II mGluRagonist DCG-IV ( $n=5$ ); group III $\mathrm{mGluR}$ agonist L-AP4 $(n=11)$ and its total suppression in the presence of Bicuculline $(n=8)$. C, Box plots summarizing the onset time latency of the synaptic responses before the induction of MF IPSC LTP (MF EPSCs obtained at $-66 \mathrm{mV}$ ), in the presence of NBQX plus D-APV (MF IPSCs obtained at $-60 \mathrm{mV}$ ), and after the induction of MF IPSC LTP. D, Scatter graph of the CV ${ }^{2}$ against the mean of the normalized MFIPSPCs at 45 min after HFS for fast-spiking (green triangles) and regular-spiking (blue triangles) interneurons. The distribution of the data with respect to the identity line (dashed line) is indicative of a presynaptic locus of expression for MF IPSC LTP.E, Cumulative probability distribution of the normalized MF IPSCS slopes independently averaged for fast-spiking or regular-spiking interneurons (green or blue circles, respectively). Each circle represents an increase in the synaptic strength relative to baseline (dashed line). The start of the horizontal arrowhead represents an increase in the slope $>25 \%$ (minimum criteria for LTP). Error bars in all the panels indicate SEM. ${ }^{* *} p<0.01$; ${ }^{* *} p<0.001$ or higher statistical significance.

ANOVA; regular-spiking interneurons, $56.9 \pm 2.72 \%$ of inhibition; $p<0.001$, one-way ANOVA; Fig. $2 B$ ). In some of these experiments, bicuculline $(10 \mu \mathrm{M})$, which was perfused alone or in the presence of the mGluR agonist, completely blocked the MF-evoked responses (Fig. $2 A, B ; n=8$ ). In an additional seven stratum lucidum interneurons (two fast-spiking and five regular-spiking interneurons), highfrequency stimulation did not modify the amplitude of the MF IPSCs $(111.6 \pm 9.22 \%$ of baseline at 35 min after HFS; $p>0.1$, one-way ANOVA), although L-AP4 was able to depress the MF IPSCs by $53.45 \pm 7.2 \%$, identifying the IPSPs as responses of MF origin.

To discard that tetanic stimulation could recruit new synapses that ultimately could be responsible for the observed increase in the synaptic strength, we verified the monosynaptic nature of the responses measuring the onset latency of MF EPSCs and MF IPSCs throughout the duration of the experiments, both in the absence and presence of glutamatergic antagonists. Thus, cells that exhibited a significant increase in the onset latency after high-frequency stimulation or cells with polysynaptic responses

\footnotetext{
$\leftarrow$

(Figure legend continued.) of stimulation and the recording of an interneuron in stratum lucidum. The electrode for MF stimulation (Stim 1) was placed over the stratum lucidum or the suprapyramidal blade of the dentate gyrus, whereas local interneurons were stimulated with an electrode placed over the stratum radiatum (Stim 2). Alternate stimulation of both sites provoked IPSCS on the same interneuron. E1, Time course graphs (averaged from six independent experiments) showing that L-AP4 inhibited the IPSCs evoked by stimulation site 1 while responses of the same cells to stimulation of site 2 were not affected (F1). E2, Box plots summarizing the effect of L-AP4 on the IPSCS for MF-evoked IPSCS (top plot) and stratum radiatumevoked IPSCs (bottom plot). Right, Representative responses evoked by MF stimulation (in red) and responses to nearby interneuron stimulation (black traces).
}

were discarded from this study. As expected, we found no statistically significant differences in the latencies before and after the induction of LTP (MF EPSC latency, $1.7 \pm 0.02 \mathrm{~ms}$; MF IPSCs in the presence of CNQX and D-AP5, $1.72 \pm 0.001$; and MF IPSCs at $40 \mathrm{~min}$ after HFS, $1.73 \pm 0.01 ; p<0.2$; Fig. $2 C$ ). Last, plotting of the MF IPSC amplitude values at $40 \mathrm{~min}$ after high-frequency stimulation against their respective coefficient of variation $\left(\mathrm{CV}^{2}\right)$, exhibited a distribution close to the identity line (Fig. 1D, dashed line), indicating that the locus of expression of MF GABA LTP on stratum lucidum interneurons is presynaptic (Malinow and Tsien, 1990; Alle et al., 2001; Galván et al., 2015). Both fast-spiking and regular-spiking interneurons had a similar cumulative $p$ distribution of the potentiated responses as well (Fig. 2E).

\section{The activation of PKA and PKC signaling cascades induces potentiation of MF GABAergic responses on stratum lucidum interneurons}

Adenylyl cyclase (AC) - cAMP-PKA signaling has a critical role in MF plasticity of CA3 neurons. Whereas its activation with forskolin mimics the MF LTP of CA3 pyramidal cells (Weisskopf et al., 1994; Villacres et al., 1998; Calixto et al., 2003), PKA signaling has a more complex mechanism of action on CA3 inhibitory cells. In stratum lucidum interneurons, MF EPSCs are insensitive to forskolin (Maccaferri et al., 1998; McBain et al., 1999), but MF EPSPs of stratum radiatum and stratum lacunosum-moleculare interneurons undergo synaptic potentiation (Galván et al., 2010, 2015). Remarkably, AC stimulation with forskolin induces the potentiation of MF IPSCs on CA3 pyramidal cells (Walker et al., 2001). Therefore, we explored whether the MF IPSC of stratum 
A
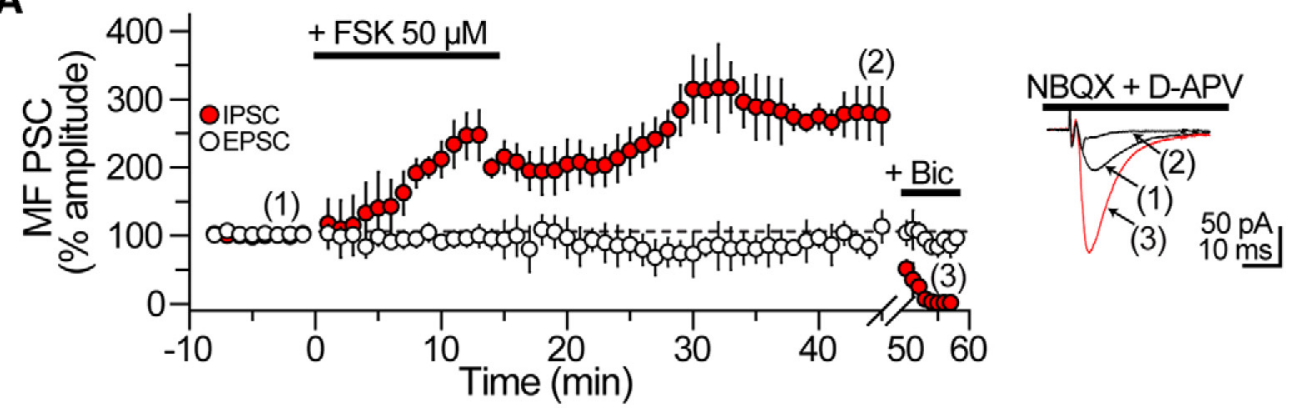

B

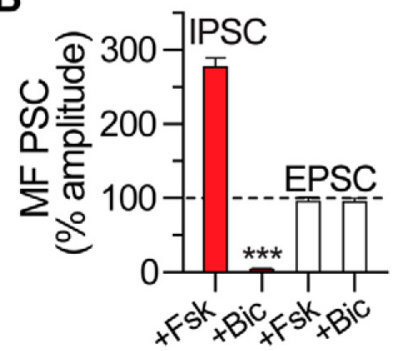

C

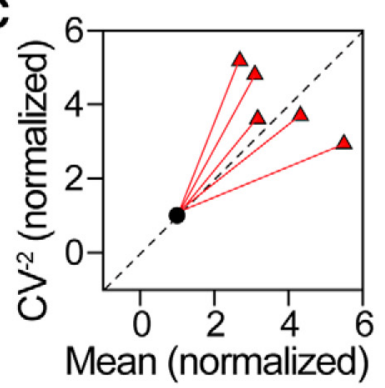

$D$

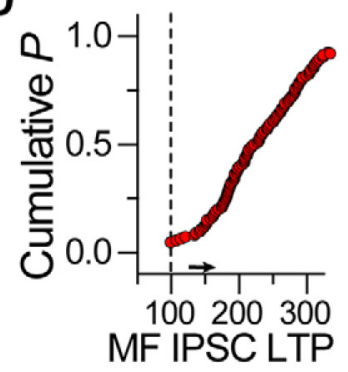

E
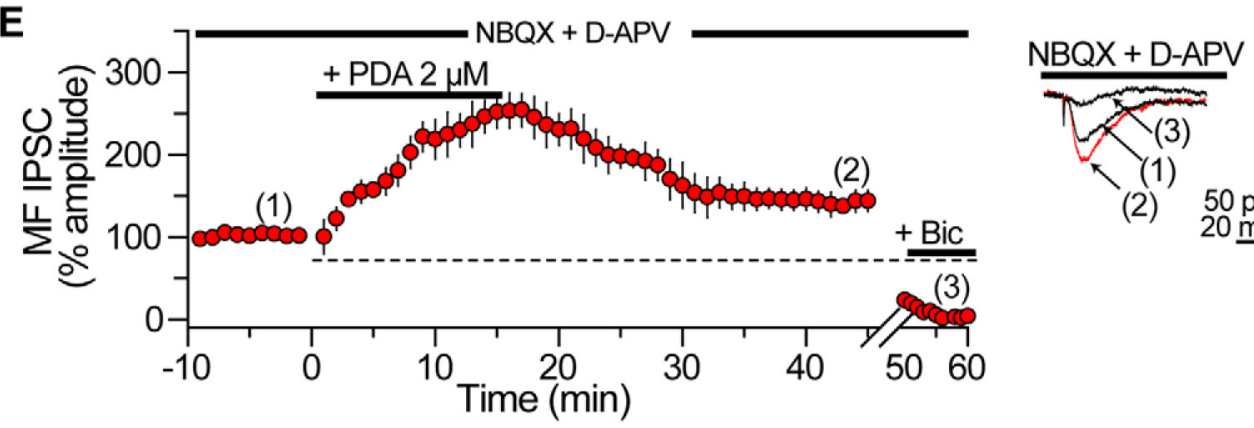

(2) $50 \mathrm{pA}$

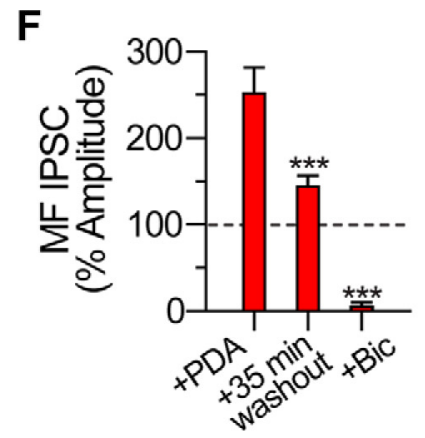

G

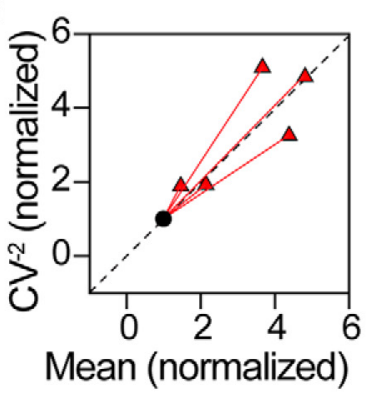

H

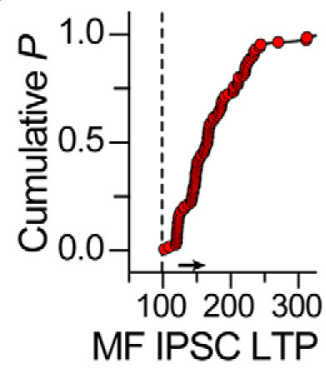

Figure 3. Stimulation of protein kinases A or C potentiates the MF IPSC on stratum lucidum interneurons. A, Time course graph of normalized slopes contrasting the effects of bath application of FSK (bar represents the period of FSK application, $15 \mathrm{~min}$ ) onto MF EPSCs (empty circles; $n=4$ ) or MFIPSCs (red circles; $n=5$ ) on stratum lucidum interneurons. The inset shows representative traces of MF IPSCs obtained at the times indicated by the numbers of the time course graph. B, Summary of the effects of FSK application on the MF IPSCs (red bars) or MF EPSCS (empty bars). MF IPSCS were completely blocked by bicuculline. $C$, The distribution of the scatter plot resulting from the $\mathrm{CV}^{2}$ vs normalized IPSCs with respect to the identity line (dashed line) indicates that FSK-mediated potentiation of IPSCS is of presynaptic origin. $\mathbf{D}$, Cumulative probability distribution. The dashed line represents baseline values; the arrowhead indicates an increase in the slope of the MF IPSC $>25 \%$. $E$, Averaged time course graph summarizing the MF IPSC potentiation induced with the PKC activator PDA ( $n=5)$. The inset shows traces of MF IPSCS (averaged from five consecutive traces) obtained at the times indicated by the numbers on the time course graph. $\boldsymbol{F}$, Summary of the PDA effects on the MF IPSCs of stratum lucidum interneurons. G, The distribution near the identity line of the CV ${ }^{2}$ vs normalized IPSCS indicates that the PKC-mediated potentiation of MF IPSC has a presynaptic origin. $\boldsymbol{H}$, Cumulative probability distribution of MF IPSC slopes after the treatment with PDA. The arrowhead indicates an increase in the slope of the MF IPSC $>25 \%$. Error bars in all the panels indicate SEM. ${ }^{* * *} p<0.001$ or higher statistical significance.

lucidum interneurons is sensitive to forskolin stimulation $(50 \mu \mathrm{M}$ for $15 \mathrm{~min}$ ). In agreement with previous reports (Maccaferri et al., 1998; McBain et al., 1999), forskolin caused a mild synaptic depression or failed to induce potentiation of the glutamatergic transmission on stratum lucidum interneurons $(82.1 \pm 15.1 \%$ of baseline $45 \mathrm{~min}$ after forskolin; $p>0.1, n=4$; Fig. $3 A$, empty circles). Opposite to the lack of effects of forskolin stimulation on
MF EPSCs, in another group of cells of stratum lucidum the isolated MF-evoked IPCSs exhibited a robust and sustained increase that lasted up to $45 \mathrm{~min}$ after the washout of forskolin $(276.7 \pm 12.1 \%$; $p<0.001, n=5$; Fig. $3 A$, red circles, $B-D)$. As expected for the transmission of MF origin, L-AP4 depressed MF IPSC potentiation $(10 \mu \mathrm{M} ; 51.3 \pm 3 \%$ of inhibition; $p<0.01$, one-way ANOVA; $n=3$; data not shown), and responses were 
blocked with bicuculline ( $10 \mu \mathrm{M} ; 98.12 \pm 0.4 \%$ of inhibition; $p<$ 0.001 , one-way ANOVA; $n=5$; Fig. $3 A, B)$.

Similar to PKA, PKC also strengthens glutamatergic transmission at MF synapses onto pyramidal cells and interneurons (Son and Carpenter, 1996, Honda et al., 2000; Alle et al., 2001; Hussain and Carpenter, 2005; Galván et al., 2010, 2015). PKC has also been implicated in the control of inhibitory transmission of the hippocampus (Rodríguez-Moreno and Lerma, 1998). Hence, we examined the role of PKC stimulation with a phorbol ester (PDA, $2 \mu \mathrm{M}$ for $15 \mathrm{~min}$ ) on the MF GABA transmission onto stratum lucidum interneurons. We perfused PDA after $8 \mathrm{~min}$ of a stable baseline recording of MF IPSCs. In all of the interneurons tested, PDA induced a sustained increase in the amplitude of the IPSC $(251.5 \pm 29 \%$ of baseline at $15 \mathrm{~min}$ after the onset of PDA; $p<$ $0.001)$ that persisted after the washout of the drug $(143.6 \pm 13 \%$ of baseline at $45 \mathrm{~min}$ after washout of PDA; $p<0.001 ; n=5$; Fig. $3 E-H)$. Similar to PKA, the plots of the IPSC amplitude values at $45 \mathrm{~min}$ after high-frequency stimulation against their $\mathrm{CV}^{2}$ revealed an increase in the strength of the inhibitory transmission closely distributed to the identity line (Fig. $3 G$ ), indicating that MF GABAergic LTP on stratum lucidum interneurons requires the activity of PKA and PKC, and also that this form of plasticity, like the glutamatergic one, is of presynaptic nature. Last, we preincubated hippocampal slices $(n=3)$ for 2-2.5 h with the PKA inhibitor H-89 $(10 \mu \mathrm{M})$ in combination with the PKC inhibitor $\mathrm{PKC}_{\text {myristoylated }}(50 \mu \mathrm{M})$ before the recordings commenced. Under these conditions, the chemical potentiation induced with FSK plus PDA was strongly reduced (IPSC amplitude at $10 \mathrm{~min}$ of FSK plus PDA washin, $147.7 \pm 52 \%$ of baseline; $p<0.05$; at $30 \mathrm{~min}$ washout of FSK plus PDA, $112.2 \pm 9.5$ of baseline; $p \geq 0.06$ ). In addition, the remaining IPSC was further depressed in the presence of L-AP4 (63.8 \pm 2.3 of baseline; $p<0.05$; data not shown). Furthermore, to look for occluding actions of PDA, we added it during forskolin maximal effect. This produced the forskolinpotentiated IPSCs to further increase (MF IPSC at $10 \mathrm{~min}$ of $\mathrm{FSK}=241.9 \pm 26 \%$ of control; at $10 \mathrm{~min}$ of PDA $=360.4 \pm 34 \%$ of control; $n=4$; data not shown) or the cells were irreversibly damaged on continuous stimulation $(n=7)$.

\section{Stratum lucidum interneurons simultaneously express GABAergic LTP and glutamatergic LTD}

Our voltage-clamp experiments indicate that a protocol of high frequency that induces MF (glutamatergic) LTD (Maccaferri et al., 1998; Toth et al., 2000), induces MF GABAergic potentiation on stratum lucidum interneurons. Thus, we decided to investigate whether these interneurons could simultaneously express GABAergic LTP and glutamatergic LTD sustained by the same MF input. The membrane potential of the interneurons was held at $-75 \pm 3.5 \mathrm{mV}$ in current-clamp mode to increase the amplitude of the glutamatergic responses. Then, we applied a depolarizing current step ( $1 \mathrm{~s}, 102 \pm 20 \mathrm{pA})$ to set the membrane potential to about $-65 \mathrm{mV}$, whereby a second stimulus was applied to the MF. This stimulation evoked a bicuculline-sensitive IPSP (Fig. 4A, B). A baseline of consecutive MF EPSPs/IPSPs was recorded, and Hebbian high-frequency stimulation (Urban and Barrionuevo, 1996; Galván et al., 2008) was delivered to the MFs, causing a burst of action potentials in all the cells tested (Fig. $4 A$, bottom). The Hebbian stimulation induced a sustained decrease of the MF EPSP slope and simultaneously an increase in the MF IPSP magnitude (postsynaptic responses at $35 \mathrm{~min}$ after HFS: MF EPSP, $58.8 \pm 1.5 \%$; $p<0.001$; MF IPSP, $189 \pm 4.2 \%$; $p<0.001$, one-way ANOVA; $n=5$ of 7). Bath application of bicuculline systematically blocked the MF IPSP ( $95.6 \pm 0.5 \%$ of baseline; $p<$
0.001, one-way ANOVA) without affecting the MF EPSP slope or amplitude (Fig. $4 A, B, D$ ). By measuring the onset latency for the EPSPs/IPSPs sequence before and $35 \mathrm{~min}$ after high-frequency stimulation, we corroborated that their onset latencies were similar throughout the duration of the experiments, indicating that no new synapses were recruited (Fig. 4A,E; MF EPSP latency control, $3.4 \pm 0.11 \mathrm{~ms}$; and latency at $35 \mathrm{~min}$ after HFS, $3.3 \pm 0.8$, $p<0.001 ;$ MF IPSP latency control, $3.4 \pm 0.09 \mathrm{~ms}$; and latency at 35 min after HFS, $3.3 \pm 0.07 ; p<0.001$, one-way ANOVA; $n=5$ ). In the remaining two cells, high-frequency stimulation caused a marked decrease in the latency of the IPSPs $(1.7 \pm 0.03$ $\mathrm{ms})$. These cells were, thus, discarded from the analysis. Together, these experiments demonstrate that opposite forms of synaptic plasticity may occur simultaneously on stratum lucidum interneurons, and, to our knowledge, this is the first demonstration that glutamatergic LTD and GABAergic LTP coexist in fibers coreleasing these amino acids. Moreover, this phenomenon is differentially expressed in subpopulations of inhibitory cells innervated by the MFs.

\section{Mossy fibers corelease glutamate and GABA onto interneurons in stratum radiatum, but not onto interneurons in stratum lacunosum-moleculare}

Our experiments corroborate that MF-evoked GABA signaling is present in stratum radiatum interneurons, an observation previously reported by others (Romo-Parra et al., 2003; Safiulina et al., 2006), and demonstrate that MF glutamatergic LTD and MF GABAergic LTP can be coexpressed in stratum lucidum interneurons. In our next set of experiments, we decided to investigate whether the MF IPSC onto stratum radiatum interneurons was capable of expressing potentiation. A total of 14 regularspiking interneurons was recorded in similar conditions to those previously described (Fig. 1). Resting membrane potential and input resistance values were similar to those previously reported (Safiulina et al., 2006; Calixto et al., 2008). In the presence of CNQX plus D-AP5, an MF IPSC was unmasked in 7 of 14 cells (Fig. $5 A, B$ ). The onset latency of the GABAergic response was similar to that previously described $(2.09 \pm 0.04 \mathrm{~ms})$. After a stable 8 min baseline of GABAergic responses, tetanic stimulation was delivered to the MFs. Unlike the stratum lucidum interneurons, the amplitude of the MF IPSC recorded from stratum radiatum interneurons did not change after high-frequency stimulation ( $94.31 \pm 5.4 \%$ of baseline at $30 \mathrm{~min}$ after HFS; $p>$ 0.5 ; $n=7$; Fig. $5 C$ ); nevertheless, the perfusion of L-AP4 depressed the synaptic response in a similar way to that observed in the stratum lucidum interneurons ( $48.37 \pm 3.19 \%$ of control; $p<0.01$, one-way ANOVA; Fig. 5C). Last, we found no evidence of MF GABAergic transmission onto any of the stratum lacunosum-moleculare interneurons recorded, because the $I-V$ curve coupled to MF stimulation did not reveal MF-mediated inward responses $(n=11$; Fig. $5 D)$. Consistently, the MF-evoked synaptic responses were blocked by CNQX plus D-AP5 $(n=11$; Fig. $5 E-G)$.

\section{Mossy fiber-mediated GABAergic transmission restrains the output of stratum lucidum interneurons}

In some of the preceding experiments, the depolarizing step used to uncover the monosynaptic GABAergic response caused the interneurons to fire action potentials. Moreover, we noticed that the MF stimulation restrained the occurrence of spikes up to $94 \pm$ $2.3 \mathrm{~ms}$ after the MF IPSP, a transient window of inhibition commonly associated with synaptic integration (Pouille and Scanziani, 2001; Semyanov et al., 2004). We expanded this obser- 
A

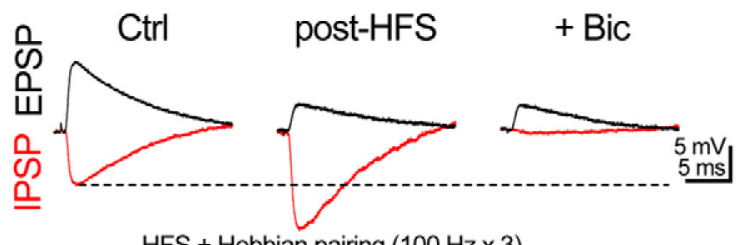

HFS + Hebbian pairing $(100 \mathrm{~Hz} \times 3)$

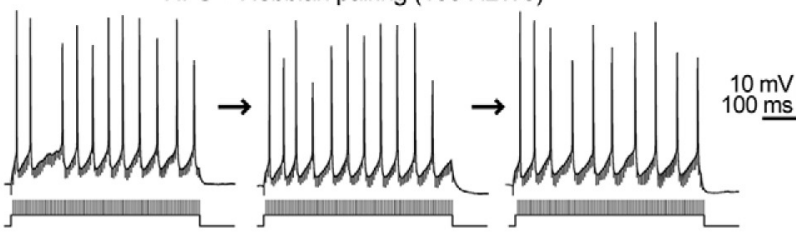

C

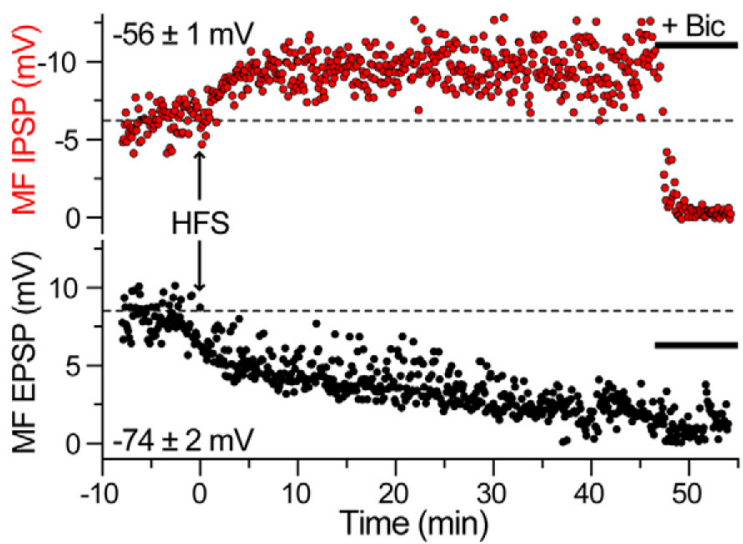

E

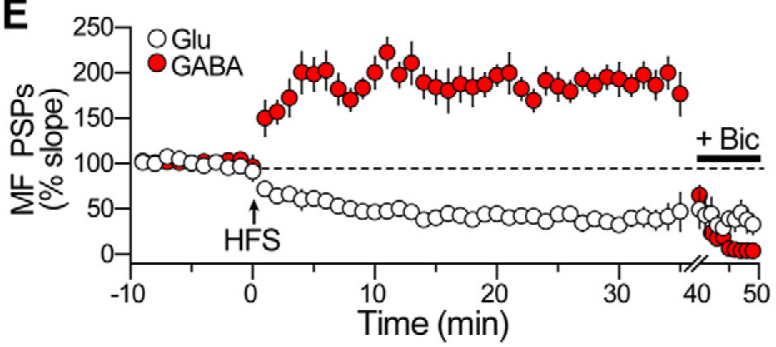

B

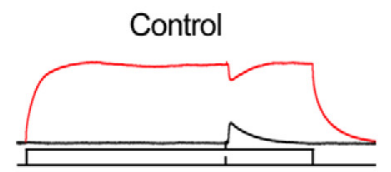

$40 \mathrm{~min}$ post-HFS
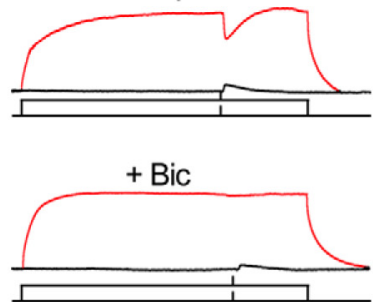

D

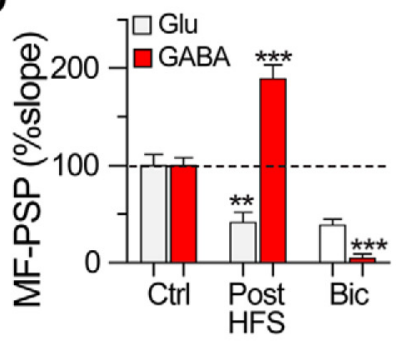

$\mathbf{F}$

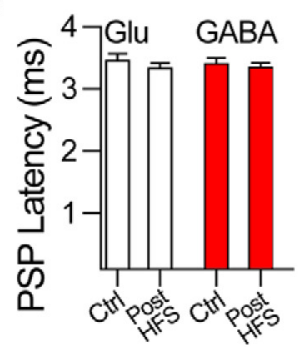

Figure 4. Glutamate and GABA signaling simultaneously express opposite forms of plasticity in stratum lucidum interneurons. A, Representative experiment showing the sequence of consecutively acquired EPSPs and IPSPs. HFS was paired with postsynaptic depolarization to achieve Hebbian stimulation (bottom; note the brief, low-voltage deflections along the traces). $\boldsymbol{B}$, Protocol used to acquire the sequence of EPSPs and IPSPs before and after HFS and after the block of glutamatergic responses. Two sweeps were consecutively acquired, the first at $-74 \mathrm{mV}$ and the second during a depolarizing pulse to reach $-55 \mathrm{mV}$ (red traces), during which MFs were stimulated. The depolarization step unmasked the inhibitory response, which could be blocked by bicuculline. C, Representative experiment showing the simultaneous expression of glutamatergic LTD (empty circles) and GABAergic LTP (red circles). Each circle represents a synaptic event acquired at $0.16 \mathrm{~Hz}$. Bath application of bicuculline (filled bar) suppressed the MF IPSP without affecting the MF EPSP. D, Summary of the effects of HFS on the normalized slopes of IPSPs (red bars) and EPSPs (empty bars). $\boldsymbol{E}$, Average time course $(n=5)$ summarizing the simultaneously induced GABAergic LTP and glutamatergic LTD obtained with HFS. $\boldsymbol{F}$, Bar graphs showing the onset latencies for the glutamatergic (empty bars) and GABAergic responses (red bars) before and after tetanic stimulation. Error bars in all the panels indicate SEM. ${ }^{* *} p<0.01 ;{ }^{* * *} p<0.001$ or higher statistical significance.

vation and explored whether a stimulation train to the MF during depolarization-dependent firing of the interneuron affected its behavior. If this were to be the case, it would indicate that GABA is released from the MF to restrain the fire pattern output of the interneurons. Cells were clamped at $-60 \pm 2.5 \mathrm{mV}$, and a strong depolarizing pulse (150 $\pm 15 \mathrm{pA}, 3.5 \mathrm{~s}$ duration $)$ produced a burst of action potentials. A brief train of MF stimulation (15 pulses at 20 or $40 \mathrm{~Hz}$ ) was delivered $900 \mathrm{~ms}$ after the beginning of the depolarizing pulse. We hypothesized that GABA released from the MFs would restrain the occurrence of action potentials in stratum lucidum interneurons, probably by causing shunting inhibition (Banke and McBain, 2006; Romo-Parra et al., 2008). The number of action potentials and instantaneous firing frequency were assessed before, during, and after the MF stimulation. In control conditions, the cells exhibited a regular spiking and accommodation fire pattern, as summarized in Table 1 and Figure 6A1-A3. By contrast, MF stimulation at $20 \mathrm{~Hz}$ caused a significant decrease in the number of action potentials and instantaneous firing frequency. Moreover, after the MF stimulation, a slight increase in the number of action potentials and the instantaneous firing frequency was observed (Table 1, Fig. 6B1-B3). The suppression of action potentials, the inhibition of instantaneous firing frequency, as well as the rebound after MF stimulation was even more pronounced when synaptic stimulation was set to $40 \mathrm{~Hz}$ (Table 1, Fig. 6C1-C3). The shunting of action potentials was observed in 9 of 13 regular-spiking cells distributed through the stratum lucidum and border with the stratum radiatum. Fast-spiking cells expressing GABA responses were discarded from this analysis as the $3.5 \mathrm{~s}$ depolarizing pulse 
A

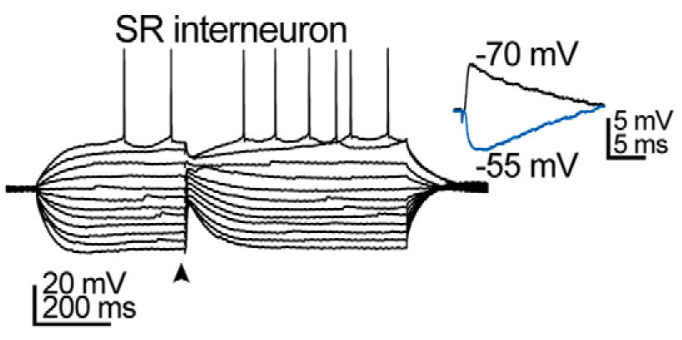

C

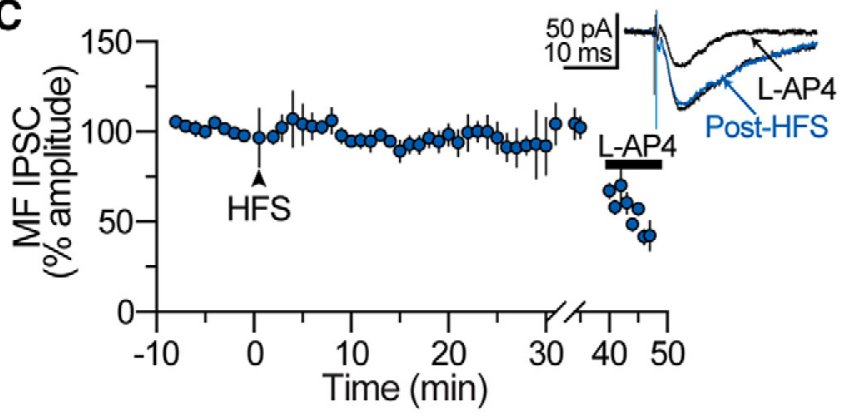

B

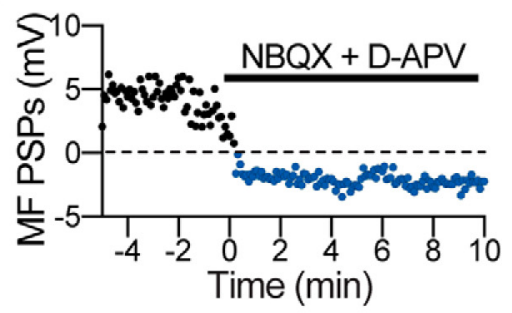

E

SL-M interneuron

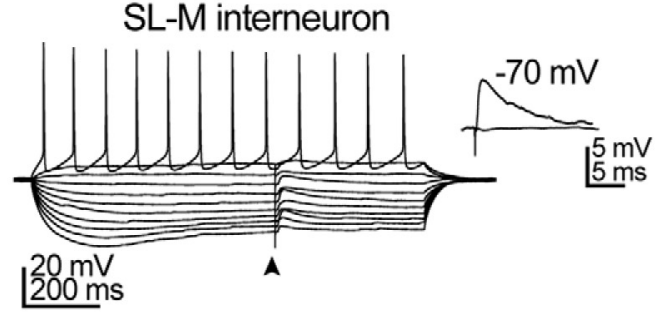

D

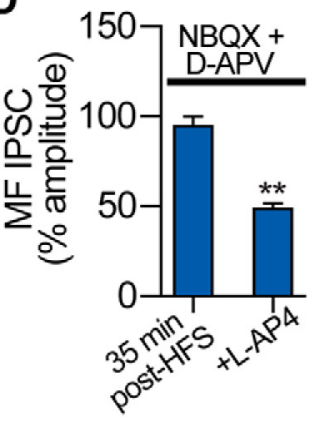

F

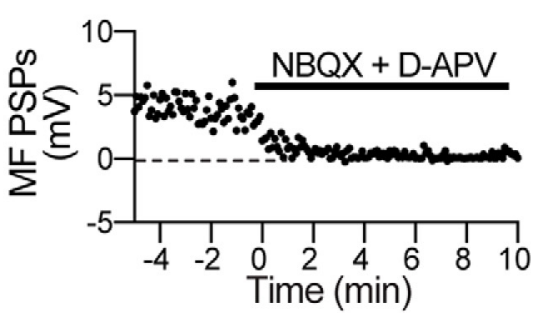

G

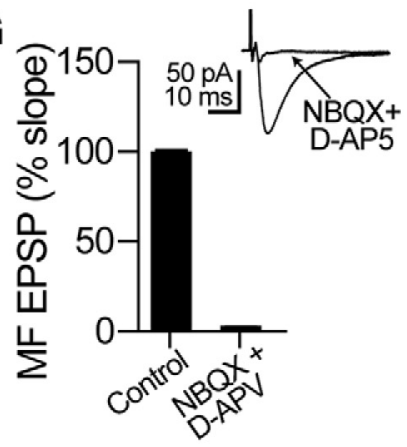

Figure 5. Mossy fiber activation evokes nonplastic IPSPs in interneurons of stratum radiatum, but not in interneurons of stratum lacunosum-moleculare. $A$, Synaptic responses evoked by MF stimulation during an $I-V$ curve of a stratum radiatum interneuron; the arrowhead under the voltage traces indicates MF stimulation. Inset depicts postsynaptic responses at different membrane potentials. B, Perfusion of NBQX and D-APV blocked the MF-evoked EPSPs and isolated a reliable IPSP. C, Average time course graph showing the lack of potentiation of the IPSPs of stratum radiatum interneurons. The IPSPs were sensitive to the bath application of L-AP4. The inset shows the IPSCS (averaged from five consecutive sweeps) in control conditions, $35 \mathrm{~min}$ after HFS (blue trace), and in the presence of L-AP4. D, Summary of the slope change of the IPSPs after HFS and during perfusion of L-AP4 ( $n=7$ ). $\boldsymbol{E}$, Synaptic responses evoked by MF stimulation during an $I-V$ curve of an interneuron in stratum lacunosum-moleculare; the arrowhead under the voltage traces indicates MF stimulation. The inset depicts postsynaptic responses at different membrane potentials where, contrary to interneurons located in stratum lucidum and stratum radiatum, interneurons in stratum lacunosummoleculare did not respond with an IPSP on MF stimulation. $\boldsymbol{F}, \mathbf{G}$, Perfusion of NBQX plus D-APV completely blocked the synaptic responses $(n=11)$. The inset shows a representative response acquired in voltage-clamp mode. Error bars in all the panels indicate SEM. ${ }^{* *} p<0.05$ or higher statistical significance. SR, Stratum radiatum; SL-M, Stratum lacunosummoleculare.

caused them to fire brief and irregular bursts of action potentials intercalated with silent periods.

Contrary to this observation, MF stimulation on regular-spiking interneurons of stratum radiatum and stratum lacunosum-moleculare that lacked GABA transmission $(n=7$ and $n=14$, respectively; Fig. $6 D 1, E 1, F 1$, blue traces) exhibited an increase in the number of action potentials that closely matched the actual MF stimulation frequency. The changes in the number of action potentials and instantaneous fire frequency of stratum lucidum interneurons that exhibited glutamate release from the MFs are also summarized in Table 1 and Figure 6F1-F3.

Last, MF-evoked responses of CA3 interneurons $(n=113)$ in stratum lucidum and stratum radiatum of animals that were
$35 \mathrm{~d}$ of age exclusively consisted of glutamate-mediated EPSCs (Galván et al., 2015). The different patterns of EPSP/spike coupling observed in the interneurons upon MF stimulation are summarized in the traces of Figure $7 A 1-A 4$. In stratum lucidum interneurons, GABA release from the MFs shunted the generation of action potentials, and, upon sustained depolarization, synaptic potentials reversed from depolarizing to hyperpolarizing (Fig. 7A1), whereas glutamate-only release from the MFs on interneurons of stratum lucidum and stratum radiatum evoked bursts of action potentials (Fig. $7 A 2, A 3)$. On the other hand, GABA corelease was totally absent on the MF synapses onto interneurons of stratum lacunosum-moleculare (Fig. 7A4). 


\begin{tabular}{|c|c|c|c|}
\hline & $\mathrm{T} 1$ & $\mathrm{~T} 2$ & $\mathrm{~T} 3$ \\
\hline & No stimulation & MF stimulation & No stimulation \\
\hline \multicolumn{4}{|c|}{ MF stim (Glu/GABA correlease) } \\
\hline AP number & $45 \pm 5$ & $30 \pm 3^{*}$ & $22 \pm 3^{*}$ \\
\hline IF Freq (Hz) & $14.2 \pm 2$ & $10.3 \pm 1$ & $8.4 \pm 1$ \\
\hline \multicolumn{4}{|l|}{$20 \mathrm{~Hz}$ stimulation } \\
\hline AP number & $36 \pm 10$ & $24 \pm 12^{*}$ & $48 \pm 12^{*}$ \\
\hline IF Freq (Hz) & $12.6 \pm 3$ & $1.1 \pm 1.5^{*}$ & $11.8 \pm 1.4^{*}$ \\
\hline \multicolumn{4}{|l|}{$40 \mathrm{~Hz}$ stimulation } \\
\hline AP number & $33 \pm 7$ & $2 \pm 1^{* *}$ & $55 \pm 7^{* *}$ \\
\hline IF Freq (Hz) & $20.5 \pm 3.2$ & $0.94 \pm 0.6^{* *}$ & $14.7 \pm 1.8^{*}$ \\
\hline \multicolumn{4}{|l|}{ MF Stim (Glu only) } \\
\hline AP number & $51 \pm 4$ & $26 \pm 3^{*}$ & $23 \pm 3^{*}$ \\
\hline IF Freq (Hz) & $20.9 \pm 7.1$ & $12.43 \pm 2.4$ & $11.7 \pm 1.2$ \\
\hline \multicolumn{4}{|l|}{$20 \mathrm{~Hz}$ stimulation } \\
\hline AP number & $38 \pm 5$ & $45 \pm 4^{*}$ & $33 \pm 4$ \\
\hline IF Freq (Hz) & $18.5 \pm 4$ & $24.5 \pm 4^{*}$ & $15 \pm 2.4$ \\
\hline \multicolumn{4}{|l|}{$40 \mathrm{~Hz}$ stimulation } \\
\hline AP number & $30 \pm 4$ & $50 \pm 1^{*}$ & $21 \pm 4$ \\
\hline IF Freq (Hz) & $24.13 \pm 4$ & $40.5 \pm 2.2^{* *}$ & $19 \pm 3.3$ \\
\hline
\end{tabular}

By contrast, interneurons receiving an exclusively glutamatergic input (blue traces in Fig. 6) fire AP in a frequencydependent manner. AP, Action potential; IF Freq, instantaneous fire frequency; MF stim, MF stimulation; T, time window. The values were obtained from the traces depicted in Fig. 6 .

${ }^{*} p<0.05$.

${ }^{* *} p<0.01$

\section{Discussion}

Here we show that the MFs corelease glutamate and GABA onto interneurons of the stratum lucidum and stratum radiatum of CA3 in hippocampal slices of juvenile rats. By contrast, interneurons of stratum lacunosum-moleculare receive exclusively the glutamatergic input. Therefore, not only giant synaptic boutons (Beltrán and Gutiérrez, 2012), but also synapses en passant and filopodial extensions (Acsády et al., 1998) can corelease glutamate and GABA.

The numerous works describing the corelease of glutamate and GABA from granule cells meet the criteria for their identification of MF origin. While some reports have suggested that GABAergic responses may have an origin that is different from MF (for review, see Münster-Wandowski et al., 2013), unambiguous, direct proof of MF coreleasing glutamate and GABA was obtained using a preparation in which pyramidal cells with MF boutons attached to their apical dendrites were isolated from the network. By direct stimulation of identified MF boutons glutamate-only, GABA-only, or mixed glutamate-GABA responses were evoked on CA3 pyramidal cells. Again, these responses displayed the signatures of the transmission of MF origin, while those obtained by stimulation of boutons of interneuronal origin lacked them (Beltrán and Gutiérrez, 2012). We show that the onset of the postsynaptic responses found in different populations of interneurons was similar for both the glutamatergic and the GABAergic components, even after block of glutamate receptors, discarding a possible disynaptic origin of the inhibitory response. Also, these responses were depressed by mGluR activation, while GABAergic transmission from interneurons is insensitive to mGluR agonist activation (RomoParra et al., 2003; Beltrán and Gutiérrez, 2012). Finally, the GABAergic component of the mixed responses disappears in animals $>25 \mathrm{~d}$ of age, as has been shown to occur in pyramidal cells. We found that not only the simultaneous gluta-
matergic-GABAergic transmission is restricted to a certain population of interneurons of stratum lucidum and stratum radiatum, demonstrating its compartmentalization, but that its plasticity is compartmentalized as well (Pelkey and McBain, 2008). MF glutamate signaling, whether alone or concomitant with GABAergic signaling, follows the plastic rules of transmission of MF origin onto interneurons (Galván et al., 2008, 2011). While interneurons in stratum radiatum receive both the glutamatergic and GABAergic signals, the GABAergic component does not undergo LTP. This contrasts with interneurons of stratum lucidum, where the GABAergic transmission undergoes a form of LTP, which coexists with glutamatergic LTD, both of presynaptic origin (Maccaferri et al., 1998). Moreover, the intracellular cascades responsible for the LTD of the glutamatergic component are also responsible for the LTP of the GABAergic one, further supporting the notion that the simultaneous glutamatergic and GABAergic transmission is of $\mathrm{MF}$ origin and that its plasticity is presynaptic. PKC activation mimics LTP of GABAergic signaling on stratum lucidum interneurons, while PKA activation also potentiated GABAergic, but not glutamatergic, responses in interneurons of stratum lucidum. Although to a lesser extent, glutamate and GABA can also convey MF transmission onto interneurons of stratum radiatum; nevertheless, this transmission is devoid of the plastic mechanisms observed in interneurons of the stratum lucidum. Postsynaptic LTP of inhibition has been shown to rely on increased synaptic $\mathrm{GABA}_{\mathrm{A}}$ receptors (Kneussel and Hausrat, 2016); however, our data are consistent with a presynaptic form of LTP that, in addition to further supporting the hypothesis of corelease of glutamate and GABA, explains a simultaneous, counterbalanced plasticity neurotransmitter release from the same MFs. We previously showed the critical role of PKA and PKC for the induction of glutamatergic LTP on several subpopulations of CA3 interneurons (Galván et al., 2010, 2015), where a postsynaptic presence for these kinases was demonstrated. Our present results indicate, however, a presynaptic locus of action for PKA and PKC on MF GABAergic transmission onto interneurons. It is possible that the intracellular location of PKA and PKC could be related to specific microdomains (possibly comprising different $\mathrm{Ca}^{2+}$ channels) on the synaptic membrane. Indeed, calcium currents on filopodial terminals synapsing stratum lucidum interneurons undergo inhibition upon induction of MF LTD (Pelkey et al., 2006). We can hypothesize the possible presence of functionally distinct vesicle pools (Walker et al., 2001; Lavoie et al., 2011), which can be selectively modulated by PKA and PKC, a mechanism that remains to be explored.

Despite the differences found in the populations of stratum lucidum interneurons (fast vs regular spiking) that we recorded, the characteristics of the GABAergic response to the Hebbian paired stimulation used in the present study is similar in both types. The filopodial extensions and the small en passant varicosities seem to be selectively tuned to match different types of interneurons, which in turn innervate different parts of the pyramidal cell somatodendritic axis, or other interneurons (Acsády et al., 1998; Szabadics and Soltesz, 2009). According to this, MF GABAergic LTP on stratum lucidum interneurons would be participating in the refinement of neuronal connectivity while still controlling the overall excitability of pyramidal cells (RomoParra et al., 2008; Beltrán and Gutiérrez, 2012), rather than depressing the inhibitory network of CA3. The impact of the corelease of glutamate and GABA on the firing output of the different interneuronal types in CA3 clearly differs from that produced by feedforward inhibition (Mori et al., 2004). Indeed, the 
A1

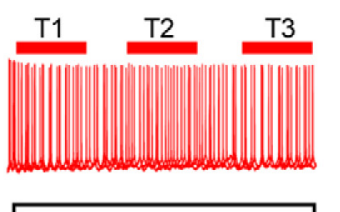

A2

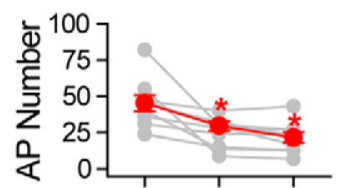

A3

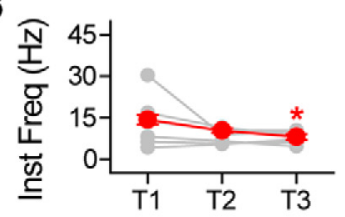

D1
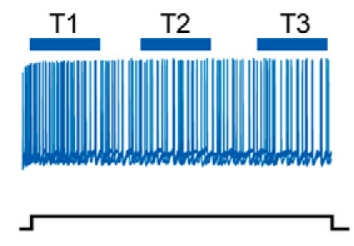

D2

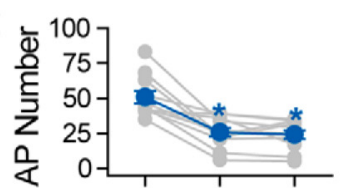

D3

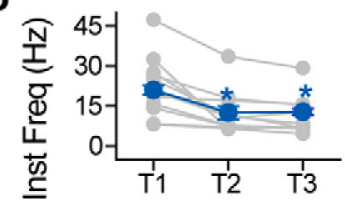

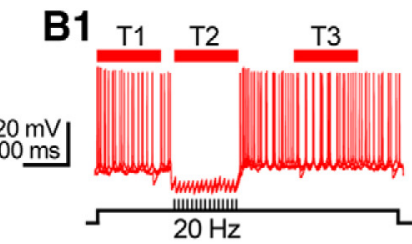

B2

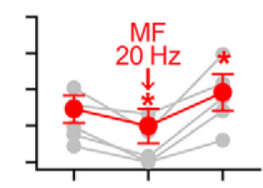

B3
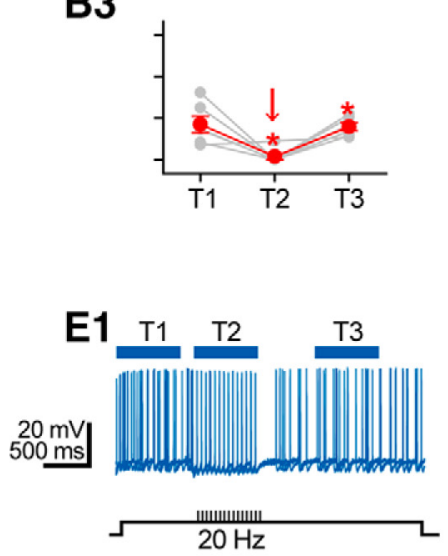

E2

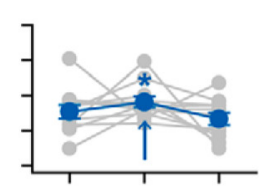

E3

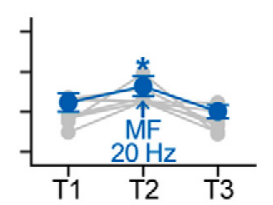

C1

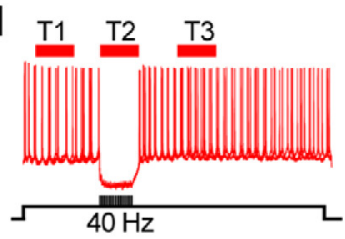

C2

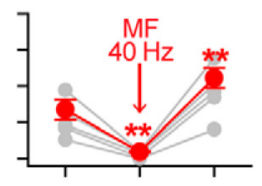

C3

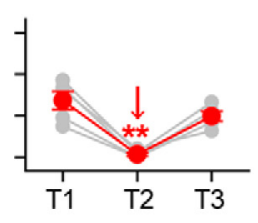

$\begin{array}{llll}\mathrm{F} 1 & \mathrm{~T} 2 & \mathrm{~T} 3\end{array}$

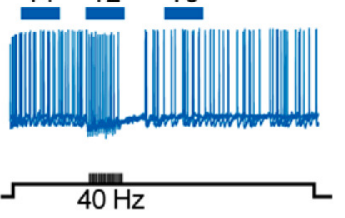

F2

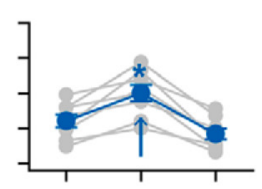

F3

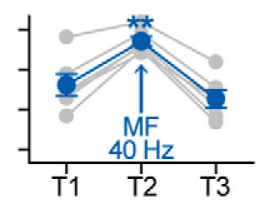

Figure 6. Corelease of glutamate and GABA from the MF differentially controls the output of $C A 3$ interneurons. A1, Sustained firing of stratum lucidum, regular-spiking interneuron was evoked by depolarizing pulses (five consecutive sweeps). B1, C1, MF stimulation (15 pulses) was applied during the repetitive firing at $20 \mathrm{~Hz}$ (B1) and $40 \mathrm{~Hz}$ (C1). The bars above the voltage traces (T1-T3) indicate the time windows in which the number of action potentials and the instant fire frequency were determined for the plots, below. A2, Plots depicting the analysis of seven stratum lucidum interneurons (gray lines; average values in red) that exhibited MF IPSPs. The negative slope in the number of action potentials and instantaneous fire frequency is indicative of adaptive fire pattern in a regular-spiking cell. $\boldsymbol{B 1}-\boldsymbol{B 3}, \mathbf{C 1}-\mathbf{C}$, Stimulation of the MFs at $20 \mathrm{~Hz}(\boldsymbol{B} 1)$ and $40 \mathrm{~Hz}$ (C1) shunted the action potential firing (B2, C2) and instantaneous fire frequency (B3, $\mathbf{C}$ ). Following the MF-evoked hyperpolarization, a systematic "rebound" in the number action potential number and fire frequency was observed in all the interneurons (T3), whereby $40 \mathrm{~Hz}$ stimulation produced a more pronounced "rebound." D1, E1, F1, By contrast, in interneurons of stratum radiatum $(n=7)$ that do not receive the MF GABAergic component, MF stimulation entrains the firing at the stimulation frequency. D2, D3, E2, E3, F2, F3, Thus, glutamate-only release from the MF caused an increase in the number of action potentials (D2, E2, F2) with an instantaneous frequency (Inst Freq; $\mathbf{D 3}, \mathbf{E 3}, \mathbf{F 3}$ ) nearing the stimulation rate applied to the MFs. Error bars in all the panels indicate SEM. ${ }^{*} p<0.05$; ${ }^{* *} p<0.01$ or higher statistical significance.

firing of action potentials of the interneurons is abolished by the hyperpolarizing action of the monosynaptic MF GABAergic input, probably underlying a reset mechanism for the CA3 microcircuit that commands the output of information from CA3. Differential plasticity of corelease onto the different target cells permits a finely tuned control of the output of the CA3 region at a developmental stage where the activation of distal dendritic $\mathrm{GABA}_{\mathrm{A}}$ receptors (originated by stratum radiatum interneurons and MF input) is still excitatory, while activation of proximal receptors (originated by stratum lucidum interneurons and MF input) restricts action potential generation (Pelkey et al., 2006; Romo-Parra et al., 2008). In pyramidal cells of the developing rodent, GABAergic inputs produce depolarizing or hyperpolar- izing responses according to the age (Gutiérrez et al., 2003; Safiulina et al., 2006) and to the site where the synapse is made, as a $\mathrm{Cl}^{-}$gradient is present along the somatodendritic axis of the developing pyramidal cells (Romo-Parra et al., 2008). Interestingly, interneurons innervating distal sites of the dendrites of CA3 pyramidal cells are still effectively recruited by MF glutamatergic inputs. Thus, presynaptically expressed GABAergic LTP on interneurons making proximal synapses ensures that feedforward inhibition does not override direct and possibly weak MF excitation, as the corelease of glutamate and GABA onto pyramidal cells can have a shunting effect (Romo-Parra et al., 2008; Beltrán and Gutiérrez, 2012). During development, GABA released from MF terminals is able to elicit action potentials in 


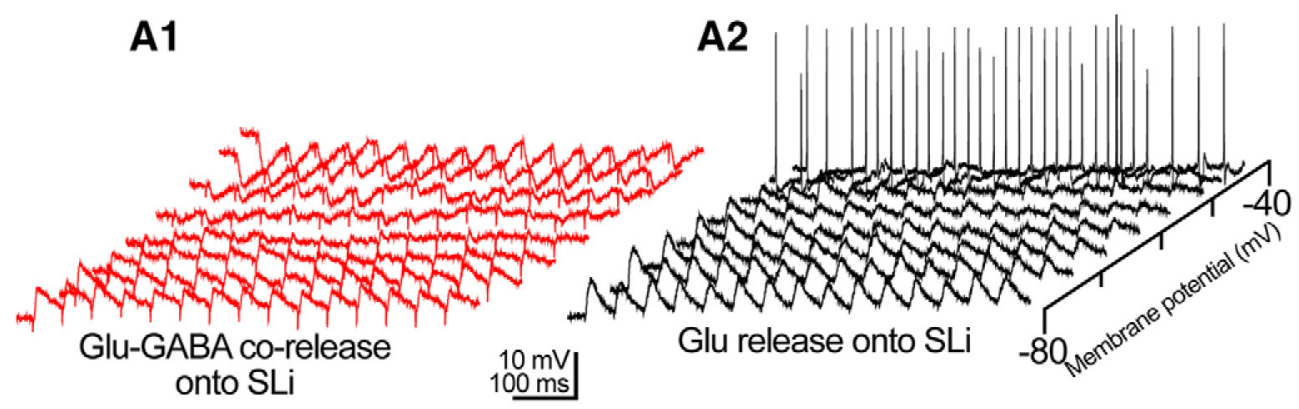

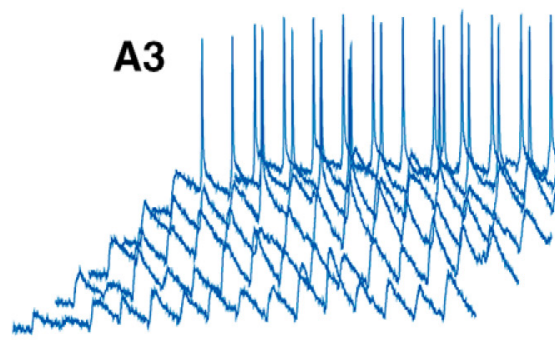

Glu release onto SRi
A4

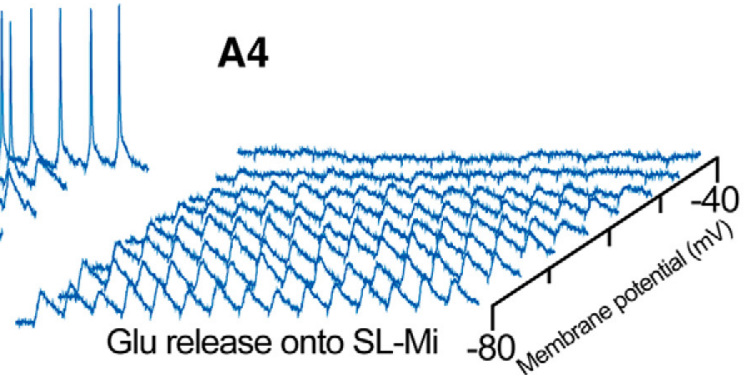

B

SL interneuron

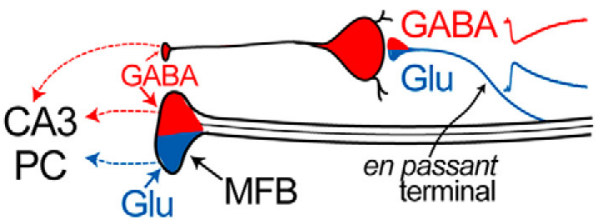

D SR Interneuron
MF GABA (no potentiation)

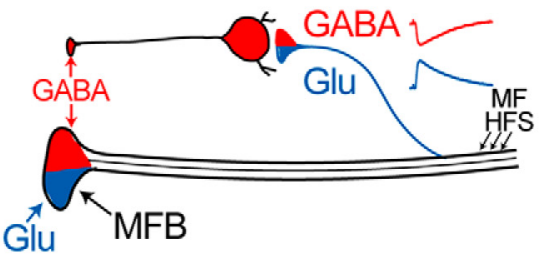

C

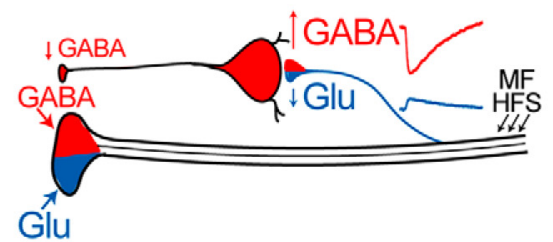

E

S L-M Interneuron Lacks MF GABA transmission

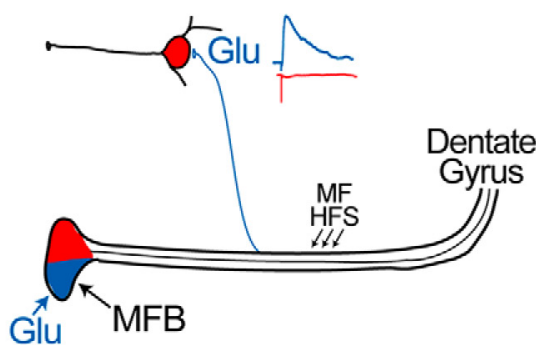

Figure 7. Patterns of MF neurotransmitter release on CA3 interneurons and probabilistic model of corelease occurrence. The membrane potential was initially held at $-80 \mathrm{mV}$ in current-clamp mode, and depolarizing steps coupled to MF stimulation were applied to unmask the MF neurotransmitter profile. A1, Stratum lucidum interneuron (SLi) exhibiting corelease of glutamate and GABA. As previously shown, the latency of the MF EPSPs and MF IPSPs did not differ. $\boldsymbol{A 2}$, In another group of stratum lucidum interneurons (see probability tree in $\boldsymbol{B}$ ), the GABA signaling was absent, in which case MF stimulation caused firing of the interneurons when held at depolarized potentials. A3, When the inhibitory response was absent in Stratum radiatum (SR) interneurons, the MF stimulation caused a temporal summation of the EPSPS, leading to the firing of action potentials. A4, Example of an interneuron in stratum lacunosum-moleculare SL-M showing MF EPSPs that were shunt at depolarized membrane potentials. $\boldsymbol{B}$, In the juvenile hippocampus, MF boutons (MFB) corelease glutamate and GABA onto pyramidal cells, while philopodia and en passant terminals of the MF corelease them onto interneurons in stratum lucidum. The compartmentalized potentiation of glutamate and GABA facilitates the induction of MF LTP on CA3 pyramidal cells, whereby HFS induces presynaptic LTD of glutamatergic transmission on stratum lucidum interneurons, reducing their excitability and restraining GABA release during the induction of MF LTP on CA3 pyramidal cells. $C$, On stratum lucidum interneurons receiving both the glutamate and the GABA inputs, tetanic stimulation yields presynaptic MF GABA LTP, which decreases the interneuron excitability, thus facilitating the induction of glutamatergic MF LTP on CA3 pyramidal cells. D, On stratum radiatum interneurons, MF GABA transmission lacks MF potentiation. The absence of plasticity on stratum radiatum cells suggests that MF GABA transmission acts as a tonic modulator of the synaptic transmission occurring on the dendritic branches of CA3 pyramidal neurons. $E$, MF stimulation did not evoke GABA-mediated responses on interneurons of the stratum lacunosum-moleculare.

targeted pyramidal cells (Safiulina et al., 2006) while exerting a shunting action on interneurons (Banke and McBain, 2006). Our data show that the activation of different second messenger cascades produces potentiation of MF GABA responses onto interneurons in stratum lucidum, and, at the same time, they pro- duce potentiation of MF glutamatergic responses onto pyramidal cells (Weisskopf et al., 1994). These data permit us to propose a mechanism of the "conservation of direction of plasticity" in the target output cells of CA3. Importantly, this is sustained by specific presynaptic intracellular signaling cascades, which match 
the way different interneuron subclasses integrate the simultaneous glutamate receptor- and GABA receptor-mediated signaling. In turn, this enables the MF and recurrent CA3 projections to maintain an effective auto-associative network functioning once MF glutamatergic input entrains it. It is noteworthy that LTD of glutamate signaling as well as GABAergic LTP signaling onto interneurons are presynaptic in origin and seem to constitute a counterbalancing mechanism. Interestingly, during the first postnatal week, the MF GABAergic, depolarizing input and postsynaptic giant depolarization potentials persistently enhance synaptic strength in MF-CA3 connections (Kasyanov et al., 2004). From the second week, however, when GABAergic signaling turns hyperpolarizing, presynaptic potentiation of GABAergic transmission onto interneurons provides the chance for CA3 pyramidal cells to be effectively recruited by MF excitation. In addition, because distal inhibition provided by interneurons of stratum radiatum and stratum lacunosum-moleculare is not restrained by MF inhibition, the filtering of distal inputs is not compromised by disinhibition. Because GABA release from the MF is a development-dependent phenomenon (Gutiérrez et al., 2003; Safiulina et al., 2006; Romo-Parra et al., 2008), we cannot rule out that MF can inhibit a higher proportion of interneurons at an earlier developmental stage, as has been shown to occur on pyramidal cells. The different patterns of MF neurotransmitter release that we disclose are schematically summarized in Figure $7 B-D$. Finally, the different probability of recording interneurons responding with monosynaptic MF GABAergic potentials in the different strata of CA3 suggests that the corelease of glutamate and GABA is a compartmentalized event during development, whereby corelease occurs only on a proportion of stratum lucidum and stratum radiatum interneurons, but not on stratum lacunosum-moleculare interneurons. In the latter, the inhibitory input will stem from other GABAergic interneurons (Gulyás et al., 1996). Therefore, glutamate-GABA corelease seems to be restricted to hierarchically selected interneurons in the juvenile hippocampus, rather than being an all-or-nothing phenomenon that should be observed in all the synapses formed by the mossy fibers. Such a selection may underlie a patterned communication of the dentate gyrus to CA3.

\section{References}

Acsády L, Kamondi A, Sík A, Freund T, Buzsáki G (1998) GABAergic cells are the major postsynaptic targets of mossy fibers in the hippocampus. J Neurosci 18:3386-3403. Medline

Alle H, Jonas P, Geiger JR (2001) PTP and LTP at a hippocampal mossy fiber-interneuron synapse. Proc Natl Acad Sci U S A 98:14708-14713. CrossRef Medline

Banke TG, McBain CJ (2006) GABAergic input onto CA3 hippocampal interneurons remains shunting throughout development. J Neurosci 26: 11720-11725. CrossRef Medline

Beltrán JQ, Gutiérrez R (2012) Co-release of glutamate and GABA from single, identified mossy fiber giant boutons. J Physiol 590:4789-4800. CrossRef Medline

Bergersen L, Ruiz A, Bjaalie JG, Kullmann DM, Gundersen V (2003) GABA and GABAA receptors at hippocampal mossy fibre synapses. Eur J Neurosci 18:931-941. CrossRef Medline

Calixto E, Thiels E, Klann E, Barrionuevo G (2003) Early maintenance of hippocampal mossy fiber-long-term potentiation depends on protein and RNA synthesis and presynaptic granule cell integrity. J Neurosci 23: 4842-4849. Medline

Calixto E, Galván EJ, Card JP, Barrionuevo G (2008) Coincidence detection of convergent perforant path and mossy fibre inputs by CA3 interneurons. J Physiol 586:2695-2712. CrossRef Medline

Galván EJ, Calixto E, Barrionuevo G (2008) Bidirectional Hebbian plasticity at hippocampal mossy fiber synapses on CA3 interneurons. J Neurosci 28:14042-14055. CrossRef Medline
Galván EJ, Cosgrove KE, Mauna JC, Card JP, Thiels E, Meriney SD, Barrionuevo G (2010) Critical involvement of postsynaptic protein kinase activation in long-term potentiation at hippocampal mossy fiber synapses on CA3 interneurons. J Neurosci 30:2844-2855. CrossRef Medline

Galván EJ, Cosgrove KE, Barrionuevo G (2011) Multiple forms of longterm synaptic plasticity at hippocampal mossy fiber synapses on interneurons. Neuropharmacology 60:740-747. CrossRef Medline

Galván EJ, Pérez-Rosello T, Gómez-Lira G, Lara E, Gutiérrez R, Barrionuevo G (2015) Synapse-specific compartmentalization of signaling cascades for LTP induction in CA3 interneurons. Neuroscience 290:332-345. CrossRef Medline

Gómez-Lira G, Lamas M, Romo-Parra H, Gutiérrez R (2005) Programmed and induced phenotype of the hippocampal granule cells. J Neurosci 25: 6939-6946. CrossRef Medline

Gulyás AI, Hájos N, Freund TF (1996) Interneurons containing calretinin are specialized to control other interneurons in the rat hippocampus. J Neurosci 16:3397-3411. Medline

Gutiérrez R (2002) Activity-dependent expression of simultaneous glutamatergic and GABAergic neurotransmission from the mossy fibers in vitro. J Neurophysiol 87:2562-2570. Medline

Gutiérrez R (2005) The dual glutamatergic-GABAergic phenotype of hippocampal granule cells. Trends Neurosci 28:297-303. CrossRef Medline

Gutiérrez R (2009) Ex uno plures: out of one, many. Co-release of classical neurotransmitters. In Co-existence and co-release of classical neurotransmitters: EX uno plures (Gutiérrez R, ed), pp 15-22. New York: Springer.

Gutiérrez R, Romo-Parra H, Maqueda J, Vivar C, Ramìrez M, Morales MA, Lamas M (2003) Plasticity of the GABAergic phenotype of the "glutamatergic" granule cells of the rat dentate gyrus. J Neurosci 23:5594-5598. Medline

Honda I, Kamiya H, Yawo H (2000) Re-evaluation of phorbol esterinduced potentiation of transmitter release from mossy fibre terminals of the mouse hippocampus. J Physiol 529:763-776. CrossRef Medline

Hussain RJ, Carpenter DO (2005) A comparison of the roles of protein kinase $\mathrm{C}$ in long-term potentiation in rat hippocampal areas $\mathrm{CA1}$ and CA3. Cell Mol Neurobiol 25:649-661. CrossRef Medline

Kasyanov AM, Safiulina VF, Voronin LL, Cherubini E (2004) GABAmediated giant depolarizing potentials as coincidence detectors for enhancing synaptic efficacy in the developing hippocampus. Proc Natl Acad Sci U S A 101:3967-3972. CrossRef Medline

Kneussel M, Hausrat TJ (2016) Postsynaptic neurotransmitter receptor reserve pools for synaptic potentiation. Trends Neurosci 39:170-182. CrossRef Medline

Lavoie N, Jeyaraju DV, Peralta MR 3rd, Seress L, Pellegrini L, Tóth K (2011) Vesicular zinc regulates the $\mathrm{Ca}^{2+}$ sensitivity of a subpopulation of presynaptic vesicles at hippocampal mossy fiber terminals. J Neurosci 31: 18251-18265. CrossRef Medline

Maccaferri G, Tóth K, McBain CJ (1998) Target-specific expression of presynaptic mossy fiber plasticity. Science 279:1368-1370. CrossRef Medline

Malinow R, Tsien RW (1990) Presynaptic enhancement shown by wholecell recordings of long-term potentiation in hippocampal slices. Nature 346:177-180. CrossRef Medline

McBain CJ (2008) Differential mechanisms of transmission and plasticity at mossy fiber synapses. Prog Brain Res 169:225-240. CrossRef Medline

McBain CJ, Freund TF, Mody I (1999) Glutamatergic synapses onto hippocampal interneurons: precision timing without lasting plasticity. Trends Neurosci 22:228-235. CrossRef Medline

Mori M, Abegg MH, Gähwiler BH, Gerber U (2004) A frequencydependent switch from inhibition to excitation in a hippocampal unitary circuit. Nature 431:453-456. CrossRef Medline

Münster-Wandowski A, Gómez-Lira G, Gutiérrez R (2013) Mixed neurotransmission in the hippocampal mossy fibers. Front Cell Neurosci 7:210. CrossRef Medline

Nicoll RA, Schmitz D (2005) Synaptic plasticity at hippocampal mossy fibre synapses. Nat Rev Neurosci 6:863-876. CrossRef Medline

Pelkey KA, McBain CJ (2008) Target-cell-dependent plasticity within the mossy fibre-CA3 circuit reveals compartmentalized regulation of presynaptic function at divergent release sites. J Physiol 586:1495-1502. CrossRef Medline

Pelkey KA, Topolnik L, Lacaille JC, McBain CJ (2006) Compartmentalized $\mathrm{Ca}(2+)$ channel regulation at divergent mossy-fiber release sites underlies target cell-dependent plasticity. Neuron 52:497-510. CrossRef Medline

Pouille F, Scanziani M (2001) Enforcement of temporal fidelity in pyrami- 
dal cells by somatic feed-forward inhibition. Science 293:1159-1163. CrossRef Medline

Rodríguez-Moreno A, Lerma J (1998) Kainate receptor modulation of GABA release involves a metabotropic function. Neuron 20:1211-1218.

Romo-Parra H, Vivar C, Maqueda J, Morales MA, Gutiérrez R (2003) Activity-dependent induction of multitransmitter signaling onto pyramidal cells and interneurons of area CA3 of the rat hippocampus. J Neurophysiol 89:3155-3167. CrossRef Medline

Romo-Parra H, Treviño M, Heinemann U, Gutiérrez R (2008) GABA actions in hippocampal area CA3 during postnatal development: differential shift from depolarizing to hyperpolarizing in somatic and dendritic compartments. J Neurophysiol 99:1523-1534. CrossRef Medline

Safiulina VF, Fattorini G, Conti F, Cherubini E (2006) GABAergic signaling at mossy fiber synapses in neonatal rat hippocampus. J Neurosci 26:597608. CrossRef Medline

Semyanov A, Walker MC, Kullmann DM, Silver RA (2004) Tonically active GABA A receptors: modulating gain and maintaining the tone. Trends Neurosci 27:262-269. CrossRef Medline

Son H, Carpenter DO (1996) Protein kinase C activation is necessary but not sufficient for induction of long-term potentiation at the synapse of mossy fiber-CA3 in the rat hippocampus. Neuroscience 72:1-13. CrossRef Medline

Szabadics J, Soltesz I (2009) Functional specificity of mossy fiber innervation of GABAergic cells in the hippocampus. J Neurosci 29:4239-4251. CrossRef Medline

Toth K, Suares G, Lawrence JJ, Philips-Tansey E, McBain CJ (2000) Differential mechanisms of transmission at three types of mossy fiber synapse. J Neurosci 20:8279-8289. Medline

Urban NN, Barrionuevo G (1996) Induction of hebbian and non-hebbian mossy fiber long-term potentiation by distinct patterns of high-frequency stimulation. J Neurosci 16:4293-4299. Medline

Villacres EC, Wong ST, Chavkin C, Storm DR (1998) Type I adenylyl cyclase mutant mice have impaired mossy fiber long-term potentiation. J Neurosci 18:3186-3194. Medline

Walker MC, Ruiz A, Kullmann DM (2001) Monosynaptic GABAergic signaling from dentate to CA3 with a pharmacological and physiological profile typical of mossy fiber synapses. Neuron 29:703-715. CrossRef Medline

Weisskopf MG, Castillo PE, Zalutsky RA, Nicoll RA (1994) Mediation of hippocampal mossy fiber long-term potentiation by cyclic AMP. Science 265:1878-1882. CrossRef Medline 